NASA Technical Memorandum 103712

AIAA-91-0661

\title{
A Review of Ice Accretion Data From a Model Rotor Icing Test and Comparison With Theory
}

Randall K. Britton

Sverdrup Technology, Inc.

Lewis Research Center Group

Brook Park, Ohio

and

Thomas H. Bond

National Aeronautics and Space Administration

Lewis Research Center

Cleveland, Ohio

Prepared for the

29th Aerospace Sciences Meeting

sponsored by the American Institute of Aeronautics and Astronautics

Reno, Nevada, January 7-10, 1991

\section{N/SA}

(NASA-TM-103712) A REVIEW OF ICE ACCRETION

N91-1342I

OATA FKOM A MOUEL ROTOR ICING TEST ANO

COMPARISON WITH THEORY (NASA) $35 \mathrm{pCSCL}$ OIA 


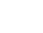

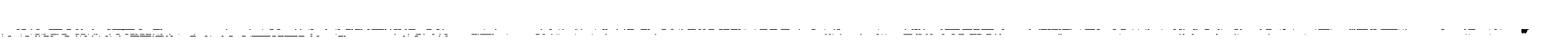

- 


\title{
A Review of Ice Accretion Data From a Model Rotor Icing Test and Comparison With Theory
}

\author{
Randall K. Britton \\ Sverdrup Technology, Inc. \\ NASA Lewis Research Center Group \\ Brook Park, Ohio \\ Thomas H. Bond \\ NASA Lewis Research Center \\ Cleveland, Ohio
}

\begin{abstract}
An experiment has been conducted by the Helicopter Icing Consortium (HIC) in the NASA Lewis Icing Research Tunnel (IRT) in which a 1/6 scale fuselage model of a UH-60A BLACK HAWK helicopter with a generic rotor was subjected to a wide range of icing conditions. The HIC consists of members from NASA, Bell Helicopter, Boeing Helicopters, McDonnell Douglas Helicopters, Sikorsky Aircraft, and Texas A\&M University. Data was taken in the form of rotor torque, internal force balance measurements, blade strain gage loading, and two dimensional ice shape tracings. A review of the ice shape data is performed with special attention given to repeatability and correctness of trends in terms of radial variation, rotational speed, icing time,temperature, liquid water content, and volumetric median droplet size. Moreover, an in depth comparison between the experimental data and the analysis of NASA's ice accretion code LEWICE is given. Finally, conclusions are drawn as to the quality of the ice accretion data and the predictability of the data base as a whole. Recommendations are also given for improving data taking technique as well as potential future work.
\end{abstract}

\section{Nomenclature}

\begin{tabular}{|c|c|}
\hline$A_{c}$ & Accumulation Parameter \\
\hline c & Chord, m \\
\hline$d_{i}$ & Local Ice Thickness, m \\
\hline f & Freezing Fraction \\
\hline $\mathbf{m}_{\mathbf{c}}$ & Mass Flow Rate Due To Impinging Liquid, kg/sec \\
\hline $\mathbf{m}_{i}$ & Mass Flow Rate Which Freezes, kg/sec \\
\hline $\mathbf{m}_{\mathbf{r}}$ & Mass Flow Rate Due To Runback, kg/sec \\
\hline $\mathbf{R}^{\mathbf{r}}$ & Blade Radius, m \\
\hline V & Local Velocity, $\mathrm{m} / \mathrm{sec}$ \\
\hline $\mathbf{v}_{\infty}$ & Freestream Velocity, $\mathrm{m} / \mathrm{sec}$ \\
\hline$\lambda$ & Liquid Water Content, $\mathrm{g} / \mathrm{m}^{3}$ \\
\hline$\Delta \mathbf{s}$ & Airfoil Segment Length, m \\
\hline$\Delta \tau$ & Icing Time, sec \\
\hline$\rho_{\mathrm{i}}$ & Ice Density, $\mathrm{g} / \mathrm{m}^{3}$ \\
\hline$\Phi$ & Azimuth Angle, deg. \\
\hline $\mathbf{n}$ & Angular Velocity, rad $/ \mathrm{sec}$ \\
\hline
\end{tabular}




\section{Introduction}

Aircraft have historically been adversely affected by bazardous atmospheric conditions. Ice accretion on werodynamic components can significantly alter the way they perform. The problem especially affects rotorcraft because of their higher sensitivity to icing than their fixed wing counterparts. In particular, a helicopter main rotor can experience dramatic increases in rotor torque in a very short icing duration. This, coupled with the fact that rotorcraft anti/deicing technology is, for the most part inadequate from system weight and power requirements, represents a very real problem for the rotorcraft industry. Currently, no U.S. made helicopter is certified to fly into known icing conditions. This forces helicopters to avoid an icing encounter, which can reduce the effectiveness of its mission. Because of this, a need has been expressed by the helicopter industry for NASA to investigate the icing process and in particular determine cost effective test techniques and improved ice protection approaches.

This industry wide interest prompted the NASA Lewis Research Center to form the Helicopter Icing Consortium (HIC) with the purpose of addressing some of the areas of interest in icing. The HIC is made up of representatives from NASA, Bell Helicopter Textron, Boeing Helicopters, McDonnell Douglas Helicopters, Sikorsky Aircraft, and Texas A\&M personnel. It was felt that the mix of government, industry, and academia with a cooperative use of each complementary area of expertise would stand a high chance of making important advances in the field of helicopter icing and result in rapid technology transfer to the user community.

The current process of certification for flight into an icing condition requires a great deal of flight testing in natural icing conditions. The extreme conditions of the icing envelope set down by the FAA are very difficult to find in nature. Thus, it would be advantageous to develop a valid technique to test these less common conditions artificially. In light of this, it was decided by the HIC to begin an ambitious program to develop a technique for testing model helicopters in the NASA Lewis Icing Research Tunnel (IRT). Thus, a two model test program was initiated for this purpose. The first, a lightly instrumented $\mathrm{OH}-58$ tail rotor was completed in the fall of 1988 . This served the purpose of verifying the fact that a rotating system could be successfully tested in the IRT and of developing many of the required test techniques. The second, a heavily instrumented Sikorsky Basic Model Test Rig (BMTR) was successfully completed in the fall of 1989. It is the intent of this report to discuss in detail one aspect of the test; that of ice accretion.

Any in depth report on ice accretion must first include a brief discussion of fundamentals. Ice accretion occurs when an aircraft flies through clouds of small water droplets which are in a supercooled state; that is, below freezing. The supercooled state is dependant on ambient temperature, droplet size, and water purity as well as other factors which will not be discussed in detail here. The actual rate of accretion on a surface is dependant on velocity, meteorological conditions, and the shape of the accreting component. The meteorological (cloud) conditions are defined in terms of the liquid water content (LWC) and temperature of the cloud as well as the droplet size of the water particles within the cloud.

The LWC is simply a measure of the water density of the cloud (in the form of droplets) and is expressed in grams of water per cubic meter of air. The LWC can, depending on type of cloud, range anywhere from 0.1 to $2.5 \mathrm{~g} / \mathrm{m}^{3}$. Stratiform type clouds with a horizontal extent between 20 and 200 miles usually exhibit a LWC ranging from 0.1 to $0.8 \mathrm{~g} / \mathrm{m}^{3}$. Cumulus type clouds, while having a horizontal extent of only between 2 and 6 miles display higher LWC; between 0.2 and $2.5 \mathrm{~g} / \mathrm{m}^{3} .^{1}$ The droplet size used herein is the volumetric median droplet size(VMD). In nature, any cloud is composed of a wide distribution of droplet sizes. For analysis purposes however, this distribution is volumetrically averaged to obtain a single representative value for an encounter. Again, depending on cloud type, typical values for VMD ranges between 10 and $50 \mu \mathrm{m}$. Stratiform clouds are usually characterized by VMDs between 10 and $40 \mu \mathrm{m}$ while cumuliform clouds are depicted by somewhat higher droplet sizes; usually 15 to $50 \mu \mathrm{m}$. An aircraft can experience an icing encounter in temperatures ranging anywhere from $0{ }^{\circ} \mathrm{C}$ to $-40^{\circ} \mathrm{C}$. Supercooled water droplets normally do not exist in temperatures below $-40^{\circ} \mathrm{C}$.

Aircraft tend to encounter two major types of ice, i.e. rime and glaze ice. Rime ice, shown in Figure 1, is the least severe of the two categories in terms of performance degradation. Usually associated with colder temperatures and lower liquid water contents, rime ice often conforms quite closely to the original contour of the airfoil. Because of this, the performance penalties are not as serious as that of glaze ice. The resulting shape closely matches that of the airfoil surface because the impinging water droplets freeze upon impact during a rime icing condition. This makes the prediction of rime ice relatively straightforward. The rime shape is usually milky white in appearance because of imprisoned air within the ice structure. Bragg $^{2}$ has identified a nondimensional parameter referred to as the Accumulation Parameter which is an indication of the total accumulation of ice. The Accumulation Parameter is defined as: 


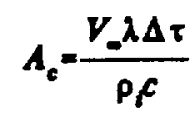

Glaze ice, shown in Figure 2, is associated with higher liquid water contents and warmer temperatures and is by far the more dangerous type of ice. Because of the wet nature of glaze ice formation the resulting shape tends to substantially distort the effective aerodynamic surface of the accreting component. The actual physics of glaze ice accretion is not well understood. Glaze ice formations severely impede the aerodynamic performance of an airfoil by causing dramatic increases in drag and decreases in lift. A major reason for the large increase in drag is the local separation which occurs past the horns of the glaze ice shape. Glaze ice also causes susceptibility to stall at lower angles of attack.

A less common category of ice is beak ice. Beak ice is a very delicate type of ice associated with warm temperatures. Similar to glaze ice, beak ice is usually manifested by a single hom on the upper airfoil surface in the region of lowest pressure. The low pressure in the suction spike drives the local temperature below freezing. Thus, ice is formed in a localized region. Beak ice formations are very fragile and aerodynamic forces will normally cause them to shed away after they reach a certain size. Thus, documentation of this type of ice is rare.

Ice accretion is a particularly difficult problem for helicopters for several reasons. With tip speeds often near 0.7 Mach number the local relative velocity of a point on the rotor is quite high. This, as shown in Equation 1 results in a very high accumulation rate for the rotor. This, coupled with the fact that design considerations must account for single engine performance significantly reduces the amount of time that a helicopter can safely stay in an icing encounter. Current requirements for icing certification state that, in the event of a deicing system failure, the unprotected helicopter must be able to maintain safe flight status for an icing duration of 15 minutes.

Thus, a powered force model test with unprotected blades in the IRT serves three purposes:

1) Computer code development and validation;

2) Development of the IRT as an icing test facility for rotorcraft;

3) Provide insight for design of rotor systems which are less sensitive to icing.

\section{Test Description}

The following is a brief description of the hardware used in the test as well as various techniques developed. A more in depth description of the test was presented in 1990 by Bond, Flemming, and Britton. ${ }^{3}$

\section{Hardware}

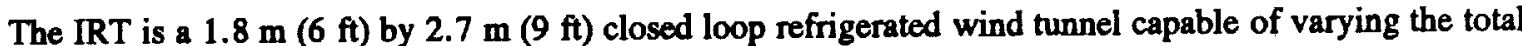
air temperature from -1.1 to $-42^{\circ} \mathrm{C}$ through the use of a 21,000 ton capacity refrigeration heat exchanger. The $4100 \mathrm{hp}$ fan allows for empty test section airspeeds up to $134 \mathrm{~m} / \mathrm{sec}(300 \mathrm{mph})$. The spray system located upstream of the test section can produce a cloud with VMDs ranging from 10 to $40 \mu \mathrm{m}$ and LWCs ranging from 0.2 to 3.0 $\mathrm{g} / \mathrm{m}^{3}$.

The Sikorsky BMTR is a general purpose rotor test rig with the power and control mechanisms as well as the load measuring system contained within the model frame. Although not used for this test, the rig does have the capability of accepting a fuselage balance and a powered tail rotor with its own balance system. The model was situated inside the tunnel such that the main rotor was located $1.01 \mathrm{~m}(3.33 \mathrm{ft})$ above the tunnel floor. This is about $0.10 \mathrm{~m}(0.33 \mathrm{ft})$ above the tunnel centerline. Although the U.S. Army UH-60A model skins used for this test are scaled for a $2.86 \mathrm{~m}(9.37 \mathrm{ft})$ rotor, tunnel constraints forced a rotor diameter of $1.83 \mathrm{~m}(6.00 \mathrm{ft})$. The rotorhead used for this test is a general purpose, four bladed, fully articulated head with a coincident flap and lag hinge offset of $76 \mathrm{~mm}$ ( $3.00 \mathrm{in})$ which corresponds to 8.3 percent of the blade radius. The pitch flap coupling for this test was zero. The BMTR main rotor was driven by a two Task 3-phase variable frequency induction electric motors. Each motor has a continuous rating of $60 \mathrm{hp}$. As installed a 3.5 to 1 reduction gear box operates the main rotor shaft to a maximum speed of $2286 \mathrm{rpm}$. This corresponds to a maximum tip speed of $219 \mathrm{~m} / \mathrm{sec}(718 \mathrm{ft} / \mathrm{sec})$. Model power was provided by a variable frequency motor generator set supplied by the Aeroflightdynamics Directorate, U.S. Army Aviation Research and Technology Activity. The main rotor blades were designed and built by McDonnell Douglas Helicopter Company using molds which were constructed by Sikorsky Aircraft. The blades 
on the $1.83 \mathrm{~m}(6.00 \mathrm{ft})$ diameter rotor have a NACA 0012 cross section and a chord of $0.124 \mathrm{~m}(4.9 \mathrm{in})$ with $-10^{\circ}$ of linear twist and no taper. The rotor blades were each numbered and marked with percentage marks for easier reference of ice extent and shedding locations.

The Dynamic Data Acquisition System (DDAS) processed and saved 41 test parameters of interest on both digital tape and floppy disks. The DDAS also derived several other parameters based on the original 41 and saved them for future analysis. The measured parameters were as follows:

\author{
Main rotor balance loads (6) \\ Main rotor torque and speed \\ Tunnel temperature,static and total pressure \\ Liquid water content \\ Control positions (4) and instrumented blade angles (3) \\ Resolved flapping and coning (3) \\ Instrumented blade flatwise (3), edgewise (4), and torsional (2) loads \\ Blade root edgewise load for each blade \\ Gimbal and rotor head accelerations (4) \\ Pushrod loads (2)
}

The Safety of Flight (SOF) system measured an additional 47 parameters and saved them temporarily in the event of a model malfunction. The main part of the digital system is the Digital Equipment Corporation PDP11/34 minicomputer. A Neff System 620 conditioned and digitized 41 of the 128 available data channels and transferred them to the PDP11. The use of simultaneous sample and hold amplifiers assured maintaining the correct time correlation of each parameter in each time frame. Because of DDAS limitations data were digitized for only the first 10 revolutions of each second. Thus, at a sample rate of 16 samples per revolution this produced a 160 point averaged snapshot for each second that data was taken.

\title{
Test Technique
}

Previous experience with the 1988 entry of the OH-58 tail rotor in the IRT provided the base for model operating and data taking procedures. The DDAS and several video systems recorded each icing run. A total of four video systems were used to provide in depth information about the blade accretion and shedding events during the run. Each of the four systems had a specific purpose: safety monitoring, blade tracking monitoring, close up imaging of rotor blades, and high speed imaging to record shedding events. The first three systems were strobe driven from a signal off of the rotor shaft to provide a frozen image. The fourth system captured shedding events using a high speed motion picture camera operating at 2000 frames/sec for a total of 21 seconds of film. As the test progressed, it became apparent that repeatability was sufficient to predict the occurrence of a shedding event on a repeat run to within \pm 5 seconds. While this improved the likelihood of capturing a shedding event on film, these efforts were still hampered by the fact that the field of view only included approximately $60^{\circ}$ azimuth of the disk plane. A total of 9 shedding events were captured on film.

During a data run, the DDAS and video systems gathered information while the tunnel conditions were monitored. Details about the LWC, including rise time and stabilization were monitored using the Johnson-Williams LWC meter. Typically, a test run began by bringing the model up to speed in order to exercise the rotor. After this was completed, the rotor was shut down to take static readings. Then, the rotor was brought back up to speed and a dynamic zero(wind off, zero lift on rotor) was taken. The model speed was reduced to a "fallback" rpm. Once the model stabilized, the tunnel conditions were set and the tunnel started. When both the tunnel conditions were set and the model was at the desired test point, an uniced baseline data burst was taken. The DDAS was then activated for the icing data sequence. Shortly thereafter (3-5 seconds) the tunnel spray system was initiated. After the spray sequence was complete the operator reduced speed to its fallback rpm to reduce the centrifugal loads on the accreted ice. The tunnel speed was then brought down. When the tunnel airspeed dropped below 10 knots the rotor was shut down. Efforts were made to reduce the time between tunnel shutdown and when the rotor could safely be stopped in order to prevent erosion of the ice shapes on the rotor. After the tunnel and model came to a complete stop, post run data was taken in the tunnel. The rotor was then de-iced and conditions were set for the next run.

It should be noted that when the conditions were set for the rotor (blade collective, shaft angle, etc.) they 
remained constant during the entire icing run. The pilot did however monitor blade flapping in order to maintain trim. Taking data in this way does present some problem when trying to relate to a natural icing test or correlate with computer methodologies. During a flight test, the controls are constantly changed during an icing event in order to maintain constant lift on the rotor. Thus, blade collective typically will increase throughout the icing encounter. Further, helicopter performance codes are usually written such that the desired forces are specified and the code will solve for the corresponding geometries, such as blade collective, shaft angle, flapping, etc. In order to alleviate this problem, a clean performance map was made early in the test. This allows the researcher to relate the iced data point to its corresponding clean point on the rotor map.

Post run information was taken in the form of $35 \mathrm{~mm}$ photographs, ice tracings, visual observations (shedding locations, type of ice, feather formation, etc.), and on some occasions ice molds. Pictures were taken of the blade planform with special emphasis on shedding locations. Close-up pictures were taken in order to document details about crack formations in the ice and ice type (rime, glaze, mixed). Close-up shots also provided information about feather formation as well as tunnel frost (if any) on the blades. A heated cutout block was pressed onto the blade a specified locations to make a slice into the ice profile. Cardboard templates were then held up against the slice and a tracing was made. This provided the two dimensional ice profile at several radial locations for correlation with ice accretion prediction codes such as LEWICE.

Test Plan

The test matrix for this test was designed to include a wide range of meteorological conditions under various performance states. The test temperatures ranged from -1.7 to $-30.5^{\circ} \mathrm{C}$ while the $\mathrm{LWC}$ varied between 0.35 and $1.24 \mathrm{~g} / \mathrm{m}^{3}$. The VMD also ranged from 13 to $23 \mu \mathrm{m}$. Icing encounter times were from 44 to 158 seconds. This simulated a wide range of rime, glaze, and mixed icing conditions. The central test condition was at $-15{ }^{\circ} \mathrm{C}, 0.50 \mathrm{~g} / \mathrm{m}^{3}$, and $15 \mu \mathrm{m}$. Performance parameters such as thrust, propulsive force, and advance ratio were changed to include the widest possible performance mapping under the above icing conditions. A total of 108 data runs were completed with 85 being icing conditions.

\section{Review of Experimental Data}

Any in depth analysis of performance penalties associated with icing must include a study of the accreted ice shapes. In an experiment of this type the quality of ice accretion data strongly reflects on the quality of all of the data. For the purposes of this paper the quality of the ice shape is defined in terms of repeatability, correctness of trends, and predictability. During the course of the test a total of 213 ice shapes were recorded as tracings, with 190 being primary shapes and 23 being secondary or post shed regrowth profiles.

\section{Repeatability}

Repeatability has traditionally been a problem in this area, particularly in natural flight testing because of the lack of control over meteorological conditions. Cloud formations are governed by nonlinear processes and therefore are almost never duplicated. Indeed, droplet distribution and concentration can vary widely under the same initial conditions. Thus, a major advantage of a facility such as the IRT is that cloud conditions can be controlled with reasonable repeatability within the tunnel. The time history of the spray conditions during a data run will directly affect the ice accretion. Thus, it is necessary to determine the repeatability of cloud conditions within the tunnel in order to assess the overall repetitiveness of the accreted ice shapes. To this end, the LWC was monitored for several data runs. It was found, as shown in Figure 3 that the LWC repeatability was quite good.

Direct comparisons of ice profiles taken at similar radial locations for repeat conditions are encouraging. Figure 4 indicates excellent repeatability for profiles taken at the $70 \%$ radial location which would correspond to rime ice for these conditions. However, as seen in Figure 5 somewhat less repeatability is seen for profiles taken further out along the blade at $90 \%$ of the span. The profile taken for run 19 seems to indicate a rime or possibly mixed ice shape whereas the profile for run 18 is more like a glaze shape. This type of disparity occurred rarely during this test. Figures 6 and 7 show excellent repeatability between profiles taken at stations corresponding to a rime condition. Similar repeatability was found for mixed conditions as shown in Figure 8. Repeatability between glaze ice shapes, while not as flawless as was experienced for rime conditions was still quite acceptable. Note, as shown in Figures 9 and 10 that the general profiles are quite similar, with some disparity in the lower impingement 
limits.

\section{Correctness of Trends}

Valuable information related to data quality can be gained from an evaluation of how the ice shape changes in response to critical parameter variations. For the purposes of this study it was determined that among all of the parameters which were varied the ones with the greatest impact on the local ice shape were radial location, rotational speed, icing time, temperature, LWC, and VMD. Thus, a discussion of how each of these parameters impacted the experimental ice shapes follows.

\section{Radial Variation}

As with any rotating system at a given rotational speed, the local velocity increases along the span with maximum velocity at the tip. This type of variation affects the local ice accretion in two ways. First, the velocity of incoming water droplets relative to the local blade station increases with span. This has the effect of increasing the local accumulation parameter linearly as velocity rises. Thus, it would be expected that the local ice shape would, in the absence of shedding grow larger in a linear fashion along the span of the blade. Higher local velocity also increases the incoming droplet inertia parameter. Droplets with higher inertia parameters would tend to be less influenced by the local flow conditions and would impact the airfoil in a straighter path. Thus, it would be expected to see a difference in impingement limits along the span of the blade. Secondly, as velocity increases the effects of aerodynamic heating become an important factor and can be significant at full scale tip speeds. This has the effect of increasing the local temperature along the radius of the blade. Thus, it would be anticipated that variation from rime, to mixed, and finally to glaze would be experienced along the span of the blade.

Figure 11 shows ice profiles taken for Run 19 at three different radial locations. The temperature for this particular run is $-24.4^{\circ} \mathrm{C}$. This temperature is quite low and this coupled with the fact that the rotational speed for this run is rather low explains why the effects of aerodynamic heating are not readily apparent in the ice shapes. However, it can be seen clearly that the local ice shape does increase in size with an increase in radial station. Because of the sparseness of the data near the lower impingement limit no real discernable trend can be seen here. Transition from rime to mixed to glaze can clearly be seen in Figure 12. While the temperature is the same for this run as for run 19, the rotational speed is quite a bit higher and the effects of aerodynamic heating are clear. Similar results are shown in Figures 13 and 14 which both clearly show transition from rime to glaze.

\section{Rotational Speed}

Variation of the rotational speed of the rotor has the effect of changing the local velocity. Thus, the trends seen here should be very similar to those discussed in the previous section on radial variation. Figure 15 shows profiles taken at the same radial location for various rotational speeds. It can be seen that the profiles corresponding to 104 $\mathrm{m} / \mathrm{s}$ and $128 \mathrm{~m} / \mathrm{s}$ follow the correct trend in that the ice shape is larger for the higher velocity because of the higher accumulation parameter. However, the profile corresponding to $119 \mathrm{~m} / \mathrm{s}$ does not follow the correct trend in that the lower impingement is not as far aft as it should be. It is possible that self shedding or post run procedures damaged the original ice shape here. Figure 16 shows results for higher velocities. Here, a clear transition from a mixed icing condition to a glaze ice shape can be seen as the glaze homs become more pronounced as velocity increases. Again, this is due to the effects of aerodynamic heating raising the local temperature of the ice accretion region.

\section{Icing Time}

Icing time has the very obvious effect of increasing the size of the ice shape the longer the exposure to icing conditions. This is illustrated in Figure 17. The ice accretion process is expected to be nonlinear in that rate of ice accretion increases with time for steady conditions, because accretion is related to exposure area. As time progresses the area of exposure increases due to previous accretion. Unfortunately, not enough data exists from this test to document this particular phenomenon here. 
Temperature is one of the most important factors in ice accretion in that it dictates the type of ice which will be formed. Warmer temperatures promote the growth of glaze ice whereas colder temperatures are associated with rime ice. Figure 18 shows profiles for temperatures ranging from $-20^{\circ} \mathrm{C}$ to $-5{ }^{\circ} \mathrm{C}$. A definite transition can be seen in that a rime shape is shown for the colder temperature and a glaze horn corresponds to the warmest temperature. It is possible that the glaze horn is actually beak ice. Similar results can be seen in Figure 19. In both cases the middle temperature, $-10^{\circ} \mathrm{C}$, corresponding to a mixed icing condition does not follow any discemable trend.

\section{Liquid Water Content}

As stated earlier, the severity of an icing encounter is directly proportional to the LWC. Thus, the higher the LWC the larger the ice shape which will be accreted. It is surprising, therefore to note Figure 20 which shows very little difference in ice shape size for different LWC's. However, the torque traces do show a correct dependence on LWC. ${ }^{3}$ This particular set of conditions represents a very short icing time, i.e. 44 seconds. It is possible that the current technique for taking ice profiles discussed earlier simply does not have the accuracy needed to pick up a noticeable trend for this short of an icing time. Figure 21 indicates, again almost no trend with LWC. It can be seen however that the profiles corresponding to LWC's of $0.75 \mathrm{~g} / \mathrm{m}^{3}$ and $1.15 \mathrm{~g} / \mathrm{m}^{3}$ follow the correct trend in that the profile for the higher LWC is slightly thicker than the other. However the profile associated with a LWC of $1.00 \mathrm{~g} / \mathrm{m}^{3}$ is largest of all. Given the uncertainties of the ice profile measurement technique it is possible that this profile is slightly inaccurate.

\section{Droplet Diameter}

VMD affects the way ice is accreted in that it directly affects the particles inertia parameter. Particles with higher inertia are less influenced by the flowfield and will fly straighter whereas lower inertia droplets tend to be deflected around the airfoil. This will affect the impingement limits in the same way as velocity, which was discussed earlier. Figure 22 illustrates this by clearly showing the lower impingement limit moving aft with increase in droplet size. Some discrepancies do exist however. Figures 23 and 24 both show an inconsistency in the lower impingement limit of the profiles corresponding to $18 \mu \mathrm{m}$ in that it is too far aft. It is possible that the majority of this lower impingement region is actually ice feathers and mistakenly included in the primary profile.

\section{Theoretical Comparison}

\section{Physical Model}

A numerical analysis, LEWICE $^{9}$ has been developed by the NASA Lewis Research Center which predicts the theoretical ice shape which accretes on a component subjected to an icing condition for a given amount of time. This analysis is composed of major steps critical in the ice accretion process, i.e.,

(1) Flowfield calculation about the component;

(2) Impingement characteristics;

(3) Modeling of the heat transfer processes;

(4) Ice accumulation normal to the surface.

Each of these important areas will be discussed briefly.

\section{Flowfield Calculation}

Calculation of the flowfield about a body which has an ice shape accretion is challenging because of the irregular effective airfoil shape which often occurs. LEWICE uses the potential flow program developed by Hess and Smith ${ }^{4}$ which makes use of distributed sources, sinks, and/or vortices to describe the flowfield about a body which has been modeled by a series line segments. Comparison of results to experimental data for clean bodies has yielded favorable agreement for the normal ranges of incompressible flow. 


\section{Impingement Characteristics}

The droplet trajectory analysis incorporated in LEWICE is based on that of Frost, Chang, Shieh, and Kimble. ${ }^{5}$ The general method has the ability to calculate trajectories and impingement characteristics of any arbitrarily shaped particle. In this particular application of the method, however, it is generally assumed that the particle is spherical and that gravity forces can be neglected, which simplifies the calculations somewhat. The reduced equation of motion is integrated using the method of Gear. ${ }^{6}$

\section{Thermodynamic Process}

The freezing process is modeled in LEWICE by performing a mass and energy balance on a control volume located on the surface and extending beyond the boundary layer. Each segment which describes the surface of the accreting component has a corresponding control volume. The runback model first developed by Messinger ${ }^{7}$ is used here. An important quantity in this analysis is the freezing fraction, which is given as:

$$
f=\frac{m_{1}}{m_{c}+m_{r}}
$$

Once the temperature and freezing fraction of the control volume are known the mass balance calculates the mass flow of the liquid runback out of the control volume. Any liquid which leaves a control volume is assumed to leave in the direction away from the stagnation point. Surface roughness strongly influences the local heat transfer processes. LEWICE uses an equivalent roughness concept which models the actual surface roughness by an average value which yields the same heat transfer characteristics. This particular aspect is widely recognized as a weak point in the analysis and much effort is currently being spent to improve the heat transfer model in general.

\section{Surface Ice Growth}

The ice accretion is assumed to grow normal to the surface. The ice growth rate can be defined using the expression for the freezing fraction and is given as:

$$
m_{i}=f\left(m_{c}+m_{p}\right)
$$

This can be redefined to yield an expression for the ice thickness as:

$$
d_{i}=\frac{m_{i} \Delta \tau \Delta s}{\rho_{i}}
$$

The iced component is then calculated by adding the corresponding ice thickness normal to each matching segment. This results in a new airfoil surface coinciding to the specified icing time.

\section{Calculation Procedure}

A helicopter rotor in forward flight will experience a rolling moment due to an imbalance in the lift on the rotor. As illustrated in Figure 25, this arises from the fact that the velocity around the azimuth varies in a sinusoidal fashion, which is given in Equation 5.

$$
V=\boldsymbol{Q} R+V_{-} \sin (\Phi)
$$

This sinusoidal velocity change affects the lift on the blade as it travels around the azimuth. Thus, lift would be higher on the advancing side and lower on the retreating side which produces a rolling moment. This moment is balanced by varying the angle of attack of the blade. Because of this, the local angle of attack is not constant. This produces a problem when applying LEWICE, a steady state code, to such a situation. Researchers have dealt with 
this particular problem in the past by developing an averaging technique which simplified their analyses. In 1983 Korkan, Dadone, and Shaw developed a technique which simplified analysis of a helicopter main rotor in forward flight with a rime ice accretion. Here, several methods of averaging were investigated and it was found that if the local Mach number and angle of attack produced by a helicopter performance code were averaged azimuthally the predicted change in performance due to rime ice accretion differed by only $\pm 2 \%$ over that of the traditional method of calculating values at specified azimuth locations around the disk. A similar averaging technique is employed in the present study. First, trimmed performance values are calculated using Boeing Helicopter's performance code B65. The local angle of attack at the radial location of interest required for trim is then averaged azimuthally. The local velocity is taken to be the rotational velocity at the specified radial location. This is, in effect, the averaged velocity. These quantities are then input into LEWICE as the velocity and angle of attack. The procedure from then on is carried out the same as any other LEWICE calculation using established guidelines for time stepping and surface roughness which are described in the LEWICE User's Manual. 9

Caution should be exercised when deciding what icing time should be used in LEWICE. It is not completely correct to use the spray time. Depending on the desired conditions, some portion of the spray time is comprised of ramp time (see Figure 3). While this ramp time can usually be ignored, it is not the case here because stabilization time takes up a significant part of the total spray sequence. This is due to the extremely short spray times used for this test. For a LWC range between 0.35 and $0.75 \mathrm{~g} / \mathrm{m}^{3}$ the spray stabilization time was seen to be approximately 20 seconds. If it is assumed that the ramp is linear from 0 to the desired LWC, the total mass flow during the 20 seconds of ramp up is the same as would be seen by 10 seconds of constant desired LWC. For example, a 54 second spray which was designed to give a LWC of $0.5 \mathrm{~g} / \mathrm{m}^{3}$ would have a 20 second ramp where the LWC varied between zero and $0.5 \mathrm{~g} / \mathrm{m}^{3}$ and 34 seconds where the $L W C$ remained constant at $0.5 \mathrm{~g} / \mathrm{m}^{3}$. The 20 second ramp would be approximated by 10 seconds at $0.5 \mathrm{~g} / \mathrm{m}^{3}$ and added to the 34 seconds. Thus, the effective icing time for a 54 second spray under these conditions would be $\mathbf{4 4}$ seconds. It should be noted that the icing times given in Table I are effective icing times obtained using this method. The assumption of a 20 second stabilization time is only valid for LWCs of $0.75 \mathrm{~g} / \mathrm{m}^{3}$ and lower. Stabilization times are much longer for higher LWCs.

Preliminary results indicated a difference in the apparent angle of accretion predicted by LEWICE and that shown by the experimental data. It has been known for some time that the B65 performance code slightly overpredicts the collective pitch angle for this experiment. Figure 26 shows a comparison between the experimental collective pitch and the prediction of B65. It can be clearly seen that B65 overpredicts the experiment by a mean value of about 1 degree. This overprediction has been independently verified using Sikorsky Aircraft's Generalized Rotor Performance (GRP) code which indicates similar results. ${ }^{10}$ It is generally thought that this discrepancy is due to interference effects of the fuselage on the rotor which are not taken into account with a free rotor analysis such as B65. In light of this, the flow angles predicted by B65 were modified by a value of 1 degree in order to better compare with the experiment. All values for angle of attack given in Table I are modified angles of attack obtained in this way.

\section{Comparisons}

Upon studying the total data base of 213 ice profiles it was found that the majority were rime ice shapes. This is due to the fact that many of the glaze shapes near the tip of the blades were shed during the run. Although many comparisons were made for both rime and glaze conditions only eight representative runs from each condition are presented here. The conditions for all the comparisons contained herein are given in Table $I$.

Rime

Results for Run 33 are shown in Figure 27. Here, it can be seen that the comparison between the prediction of LEWICE and the experiment is good. The upper impingement limit is predicted as well as the general shape. A slight underprediction does occur in the stagnation region however. Also, the lower impingement limit is overpredicted. The prediction for Run 94 shown in Figure 28 indicates similar results. Again, the general shape compares favorably with a discrepancy near the stagnation region. Figure 29, which contains results for Run 34 indicates better results. The upper impingement limit, general shape, and local thickness are all predicted very well. Although it appears that LEWICE overpredicts the lower impingement limit, nothing conclusive can be said because of the scarce data in this region. While the previous three comparisons all have shown a tendency towards underprediction of the ice thickness in the stagnation region this is generally not the case. As shown in Figures 30 
through 34, comparisons for the majority of the rime data is excellent. In many cases the predicted and experimental virtually overlap each other. A slight discrepancy on the upper surface does exist in the comparison for Run 79 shown in Figure 31. It is possible that during the ice tracing process ice feathers were inadvertently included in the general outline. Since feathers are not part of the primary ice shape LEWICE would not be able to predict these. In general, it is felt that for this test the predictability of the rime condition is outstanding and serves to further validate the experimental data.

Glaze

Historically it has always been more difficult to mathematically model the glaze condition than rime. This is due to the fact that local heat and mass transfer must be taken into account for this condition. The complex task of predicting heat transfer cocfficients as well as local surface roughness values has led to numerous empirical and approximate methods which have several shortcomings. Thus, predictions of glaze ice shapes are rarely as precise as those of rime.

It should be noted that comparison of LEWICE results to glaze shapes taken during the test were limited to Mach number less than 0.5 because of compressibility effects not currently modelled by the potential flow code used in LEWICE.9 Thus, at a tip speed of $206 \mathrm{~m} / \mathrm{s}$ comparisons were limited to shapes taken inboard of $85 \%$ blade radius. Several runs which were at a lower tip speed did allow comparison further outboard. Figures 35,36 , and 37 all illustrate similar results in that the general outline of the ice shape compares fairly well, but the thickness is overpredicted. This could, in part, be due to post accretion erosion of the ice shape. Tunnel shutdown procedures consumed several minutes before the rotor speed could be dropped to zero. During this time in which the rotor was operating in clear air it is possible that the ice shape eroded somewhst. This is substantiated to a degree by the rotor torque traces which show a drop in torque after the spray sequence is concluded. ${ }^{10}$ This erosion would be more pronounced outboard where the local velocities are highest. Thus, it would be expected that LEWICE would overpredict these cases. On a few occasions, as shown in Figures 38 and 39 LEWICE had difficulty discerning between the rime and glaze conditions. Here it can be seen that for both cases, the predicted shape is very smooth indicating a rime condition. However, the experimental data indicates glaze or possibly mixed outlines for both cases. For the most part however, the predictions of LEWICE correctly discriminated between the rime and glaze conditions. Results for Run $\mathbf{5 1}$, shown in Figure $\mathbf{4 0}$ are quite reasonable. Here, the thickness is properly predicted, as well as the general outline but with a discrepancy at both impingement limits. Some comparisons, such as those shown in Figures 41 and 42 were somewhat disappointing in that the general outline does not compare well to the experimental data. With a few exceptions, it is felt that the predictions for the glaze condition were acceptable and of as high a quality as the current state of the art allows.

\section{Summary and Conclusions}

The accretion data taken from a model rotor icing test in the IRT was reviewed in terms of repeatability, correctness of trends, and predictability. It was found that the repeatability of an ice shape between runs was excellent. This illustrates a major advantage of a facility such as the IRT in that it is possible to have much greater control over the testing environment than that of flight test. It was also found that the trends occurred in a correct manner. Some difficulty was experienced in discerning a clear trend for a change in LWC. It is possible that this is due to shortcomings in the ice tracing technique. The use of an instrument such as a pencil to trace the ice shape tends to be somewhat inaccurate especially for delicate glaze shapes which are easily damaged. It would be advantageous to develop a less intrusive technique such as a colored spray paint which would have a greater chance of noting detail and less likelihood of disfiguring the ice shape. Comparisons were made between the experimental data and the analysis of LEWICE. The angle of attack input into LEWICE had to be modified by a mean value of 1 degree because fuselage interference effects which are not taken into account by the free rotor analysis of B65 caused a discrepancy. The results for the rime condition were excellent. Results for the glaze condition were mixed with a slight tendency to overpredict the thickness. Overall, it was felt that the predictability of the ice shape data was very good.

Given the above evidence it is felt that the dataken from this experiment is valid and of high quality. Results are extremely encouraging and warrant future testing. The technique of testing powered rotorcraft in an icing tunnel shows great promise as an alternative to extensive flight testing. While flight testing will almost certainly always be a requirement, this technique, coupled with validated analytical methods can provide a means 
to minimize the emphasis on flight testing.

\section{Acknowledgement}

The authors wish to thank Montgomery Cannon for his efforts in the digitization of all of the accretion data.

\section{References}

' Bowden, D.T., Gensemer, A.E., and Skeen, C.A., "Engineering Summary of Airframe Icing Technical Data," FAA Technical Report ADS-4, 1964.

${ }^{2}$ Bragg, M.B., "Rime Ice Accretion and its Effect on Airfoil Performance," NASA CR 165599, March 1982.

${ }^{3}$ Bond, T.H., Flemming, R.J., and Britton, R.K., "Icing Tests of a Model Main Rotor," Proceedings of the $46^{\text {th }}$ Annual American Helicopter Society Forum, pp. 267-281, May 1990.

${ }^{4}$ Hess, J.L., and Smith, A.M.O., "Calculation of Potential Flow About Arbitrary Bodies," in Progress in Aeronautical Sciences. D. Kuchemann, ED. Elmsford, New York: Pergmon Press, 1967, chap. 8, pp. 1-138.

${ }^{5}$ Frost, W., Chang, H., Shieh, C., and Kimble, K., "Two-Dimensional Particle Trajectory Computer Program," Interim Report for Contract NAS3-22448, 1982.

'Gear, C.W., "The Automatic Integration of Ordinary Differential Equations," Comm. ACM 14, 1971, pp. 176-179.

${ }^{7}$ Messinger, B.L., "Equilibrium Temperature of an Unheated Icing Surface as a Function of Airspeed," Journal of the Aeronautical Sciences, vol. 20, 1953, pp. 29-42.

'Korkan, K.D., Dadone, L., and Shaw, R.J., "Performance Degradation of Helicopter Rotor Systems in Forward Flight Due to Rime Ice Accretion," AIAA Paper 83-0029, January 1983.

${ }^{9}$ Ruff, G.A., and Berkowitz, B.M., "Users Manual for the NASA Lewis Ice Accretion Prediction Code (LEWICE)," NASA CR 185129, May 1990.

${ }^{10}$ Flemming, R.J., Bond, T.H., and Britton, R.K., "Results of a Sub-Scale Model Rotor Icing Test," AIAA Paper 91-0660, January 1991. 
TABLE I. TEST CONDITIONS FOR SELECTED RUNS.

\begin{tabular}{||c|c|c|c|c|c|c|c||}
\hline \hline \multicolumn{7}{|c|}{ IRT Model Rotor Icing Test } \\
\hline \hline Run & r/R & $\begin{array}{c}\text { RR } \\
\mathrm{m} / \mathrm{s}\end{array}$ & $\begin{array}{c}\text { Temp } \\
{ }^{\circ} \mathrm{C}\end{array}$ & $\begin{array}{c}\text { LWC } \\
\text { g/m }\end{array}$ & $\begin{array}{c}\text { VMD } \\
\mu\end{array}$ & $\begin{array}{c}\text { Time } \\
\text { sec }\end{array}$ & $\begin{array}{c}\text { AoA } \\
\text { deg. }\end{array}$ \\
\hline 24 & 0.50 & 213.4 & -24.7 & 0.50 & 15 & 98 & 3.2 \\
\hline 33 & 0.50 & 213.1 & -15.3 & 0.50 & 15 & 44 & 3.5 \\
\hline 34 & 0.45 & 212.8 & -15.3 & 0.50 & 15 & 44 & 3.7 \\
\hline 41 & 0.40 & 205.7 & -15.8 & 0.50 & 15 & 70 & 3.5 \\
\hline 51 & 0.85 & 182.9 & -15.1 & 0.50 & 15 & 98 & 2.0 \\
\hline 52 & 0.90 & 182.9 & -15.1 & 0.50 & 15 & 158 & 1.6 \\
\hline 68 & 0.50 & 206.0 & -14.9 & 0.50 & 15 & 70 & 4.3 \\
\hline 71 & 0.79 & 205.7 & -15.2 & 0.50 & 15 & 70 & 2.5 \\
\hline 73 & 0.75 & 206.0 & -14.9 & 0.35 & 15 & 70 & 2.9 \\
\hline 74 & 0.50 & 205.7 & -15.5 & 0.75 & 15 & 44 & 3.3 \\
\hline 79 & 0.39 & 206.0 & -16.1 & 0.50 & 15 & 98 & 3.1 \\
\hline 87 & 0.80 & 206.0 & -15.0 & 0.50 & 15 & 70 & 2.3 \\
\hline 88 & 0.82 & 205.7 & -15.0 & 0.50 & 15 & 70 & 2.5 \\
\hline 89 & 0.85 & 205.7 & -15.0 & 0.50 & 15 & 70 & 2.3 \\
\hline 94 & 0.80 & 205.7 & -25.5 & 0.50 & 15 & 70 & 2.5 \\
\hline 97 & 0.79 & 205.7 & -15.5 & 0.50 & 15 & 70 & 2.7 \\
\hline
\end{tabular}




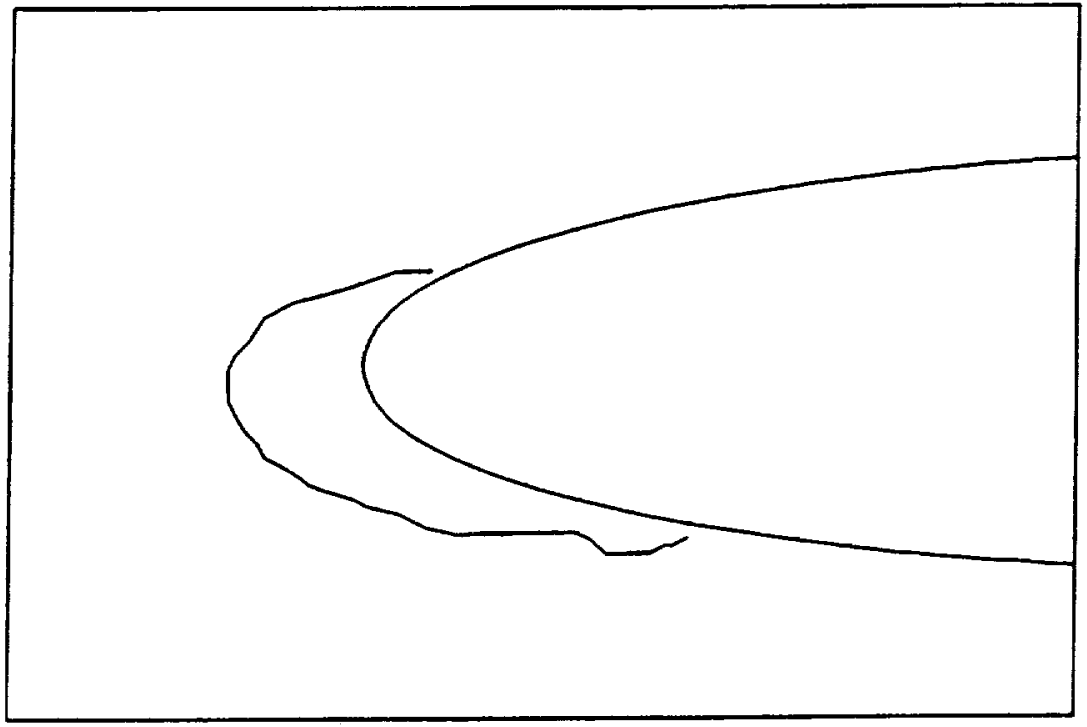

Figure 1. Rime ice shape.

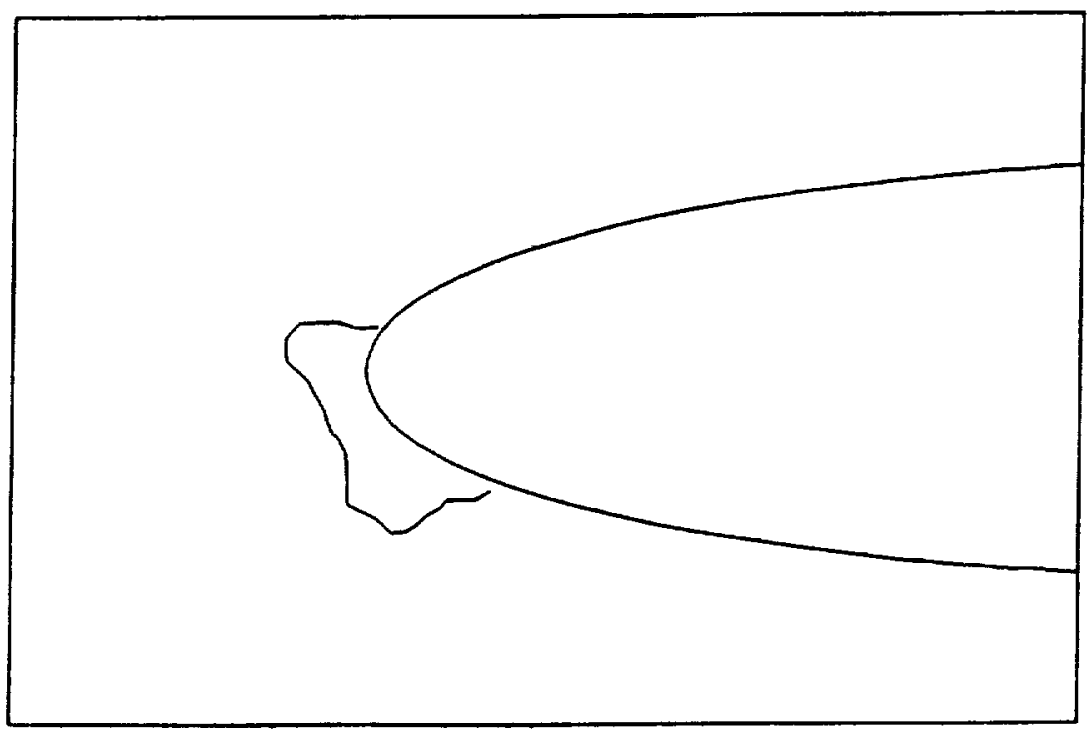

Figure 2. Glaze ice shape. 


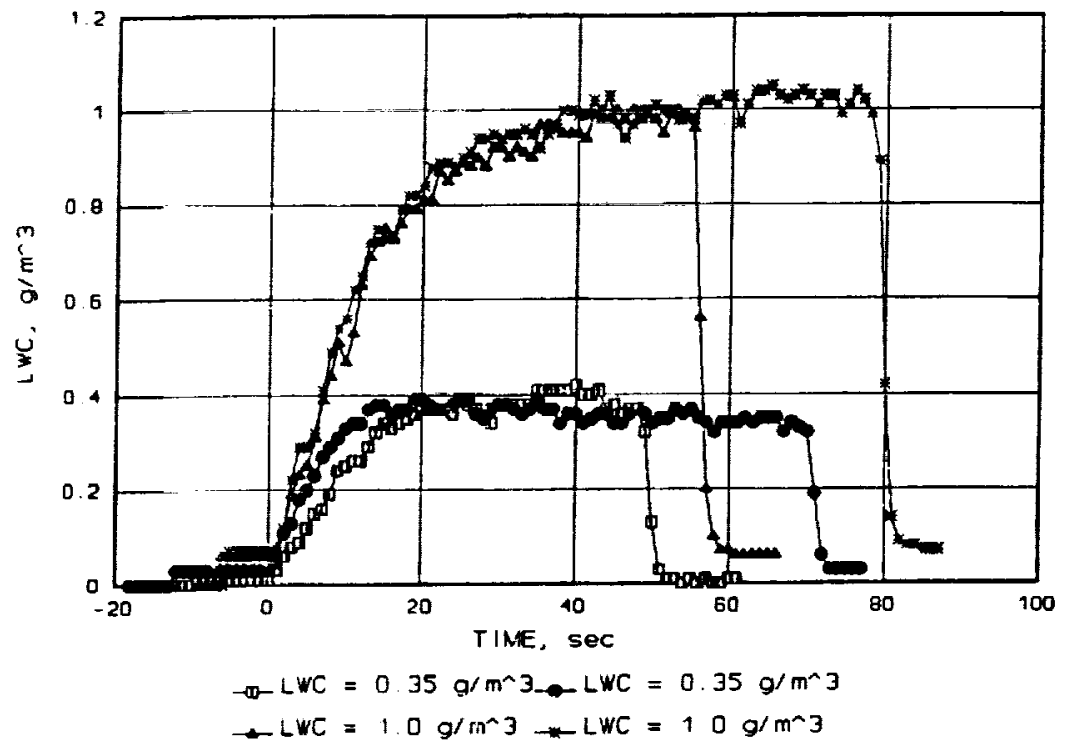

Figure 3. LWC vs. time.

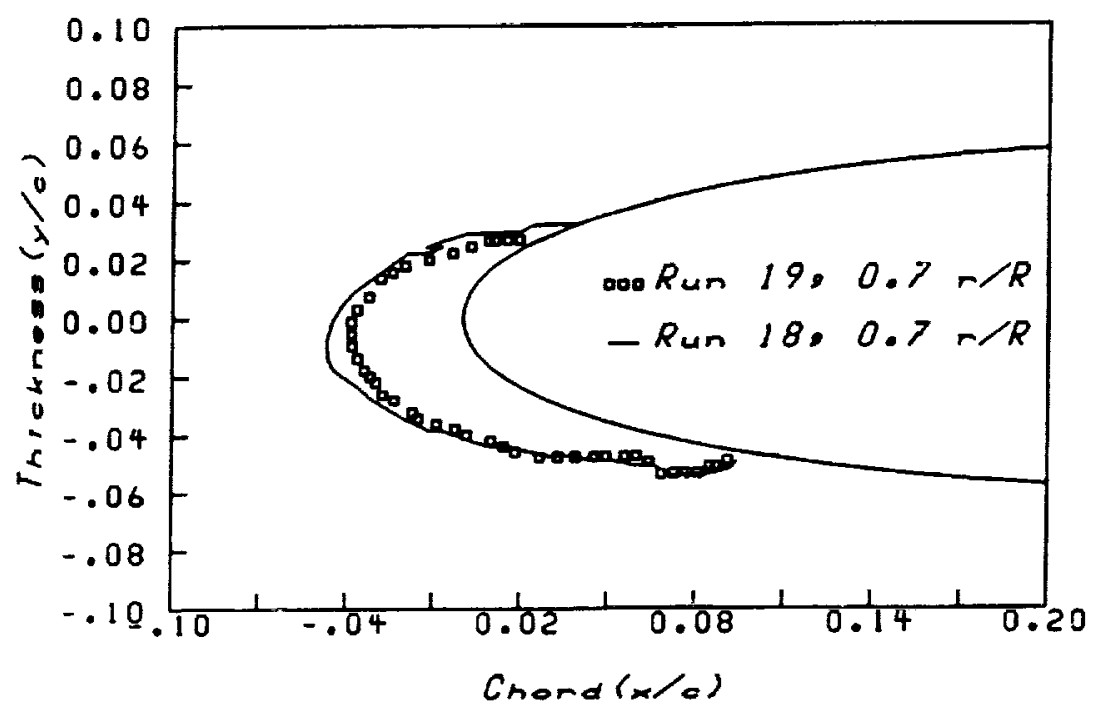

Figure 4. Ice profiles for Runs 18 and $19,70 \%$ radial location. 


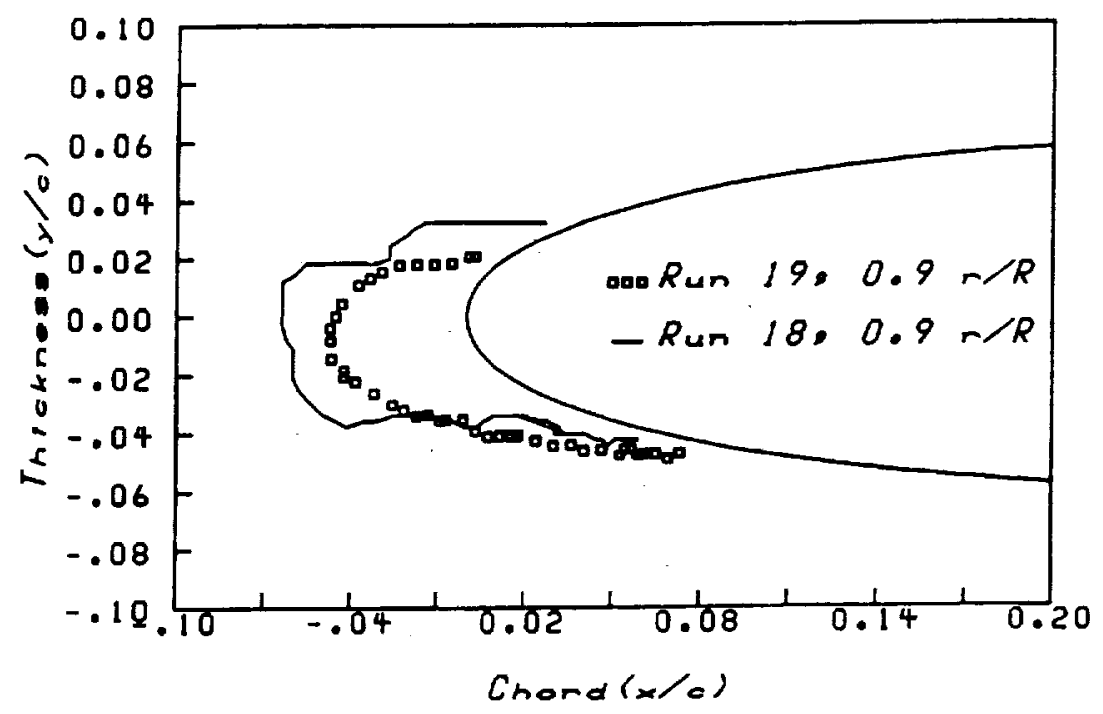

Figure 5. Ice profiles for Runs 18 and $19,90 \%$ radial location.

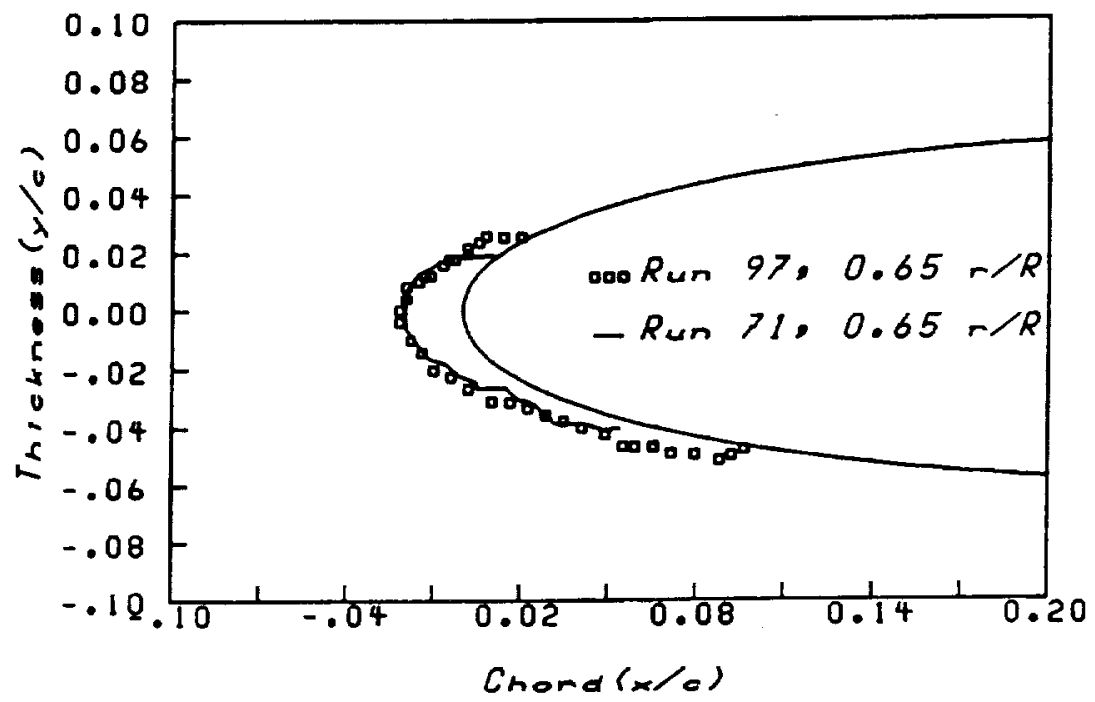

Figure 6. Ice profiles for Runs 71 and $97,65 \%$ radial location. 


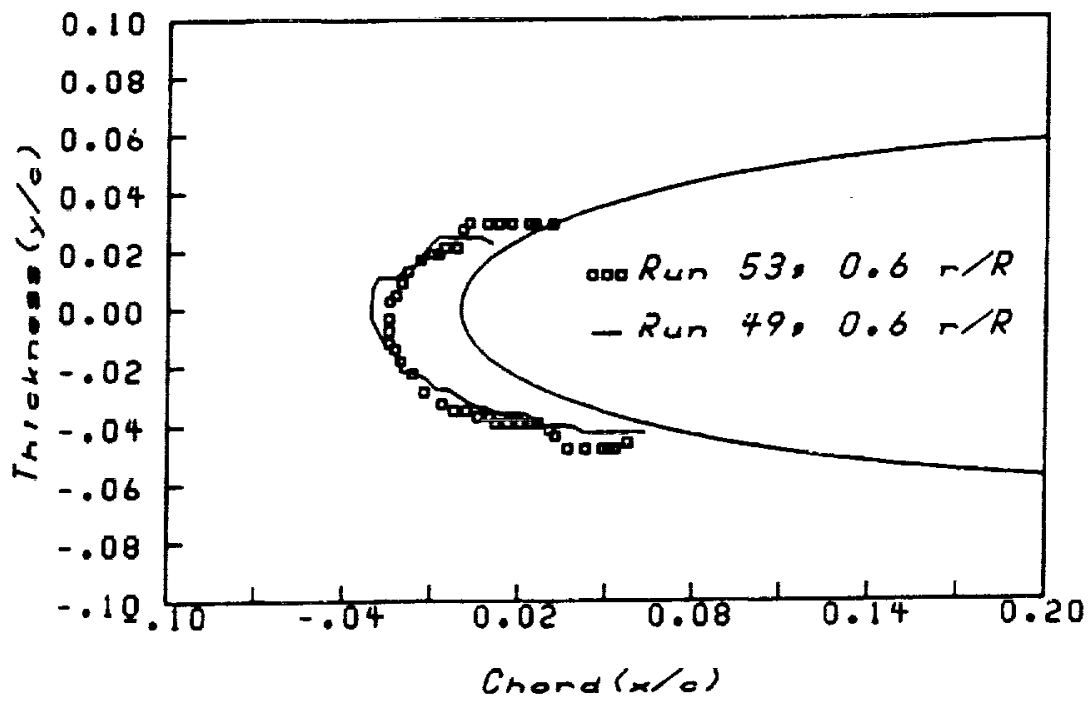

Figure 7. Ice profiles for Runs 49 and $53,60 \%$ radial location.

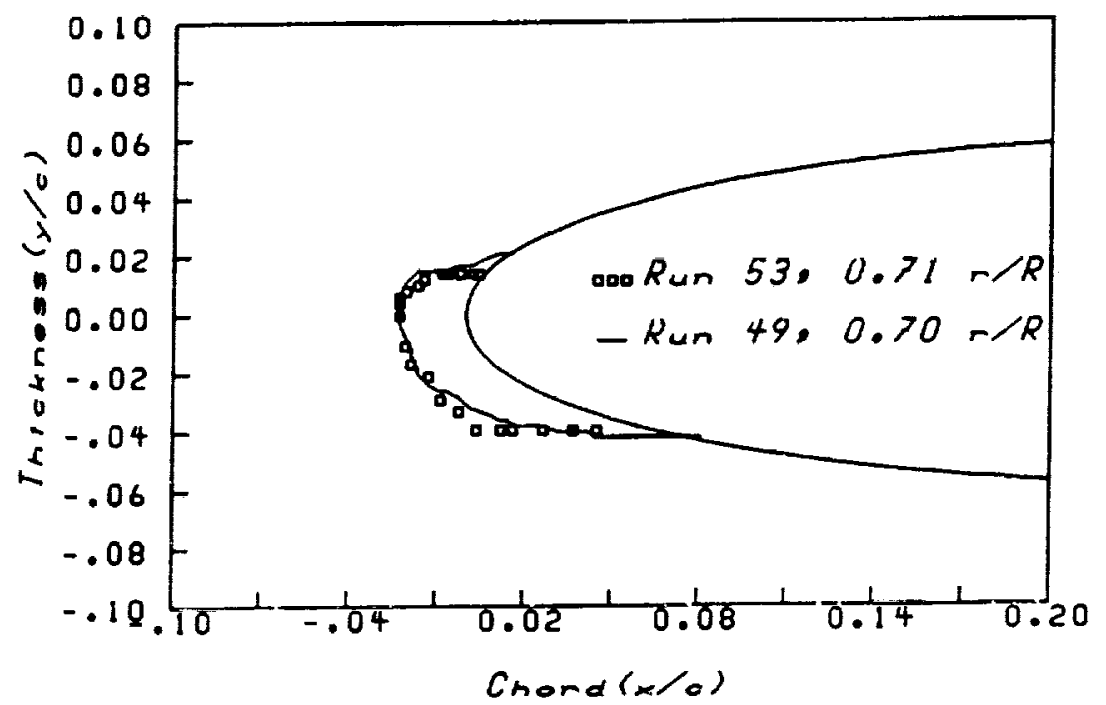

Figure 8. Ice profiles for Runs 49 and $53,70 \%$ radial location. 


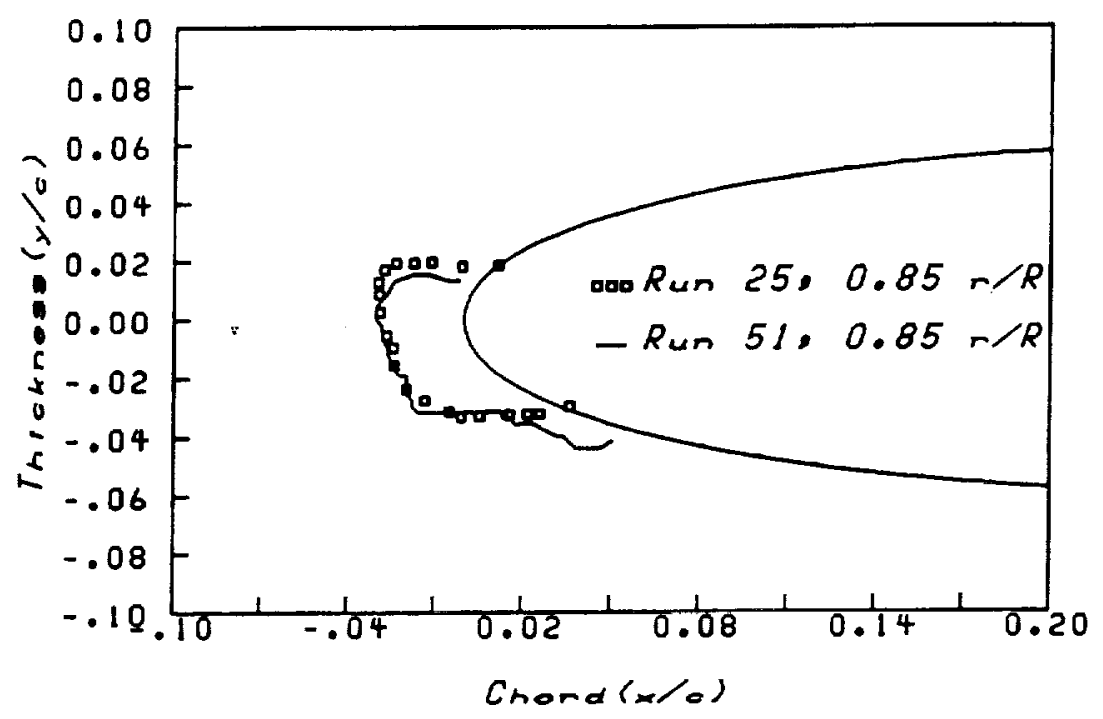

Figure 9. Ice profiles for Runs 25 and $51,85 \%$ radial location.

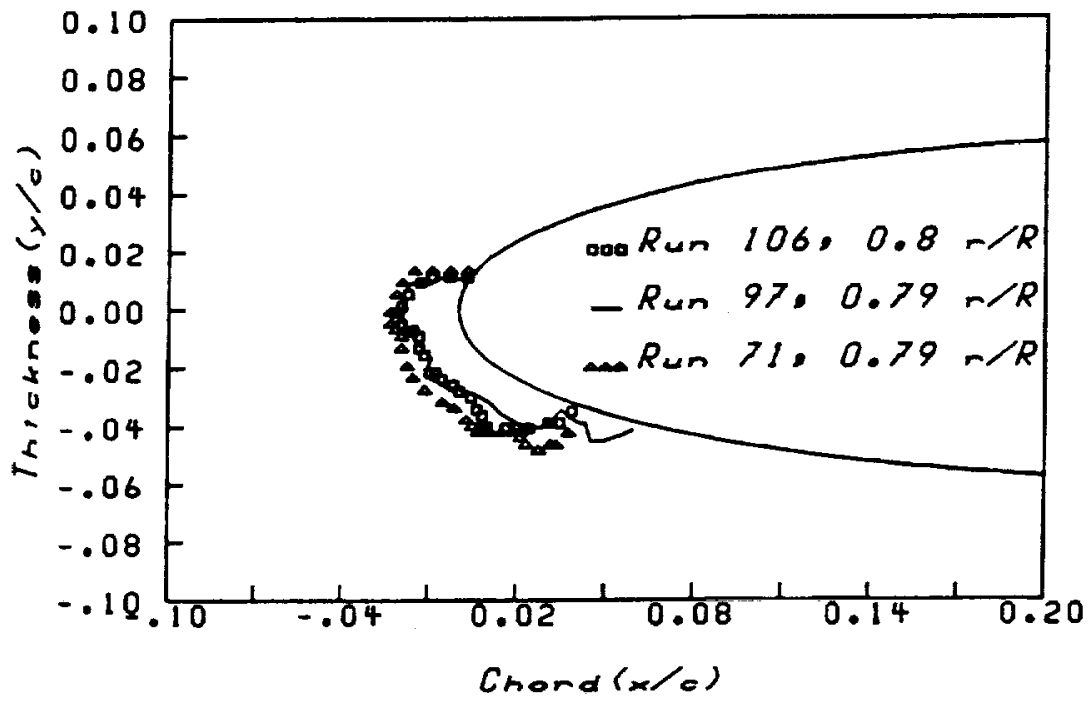

Figure 10. Ice profiles for Runs 71,97 , and 106, $79 \%$ radial location. 


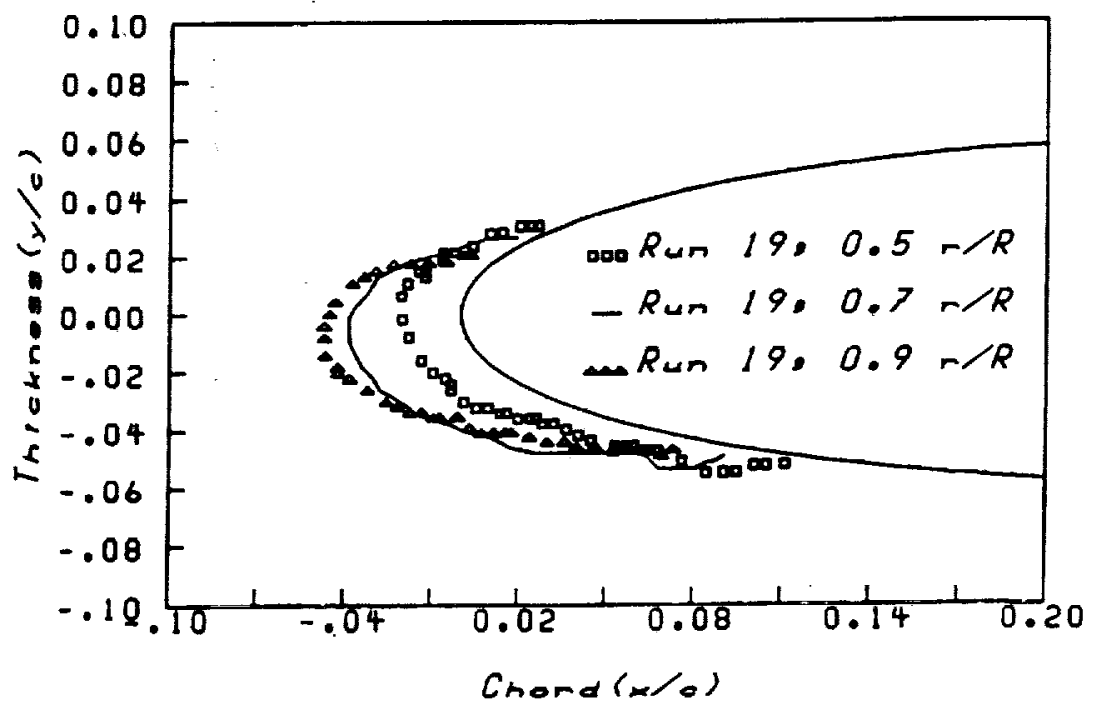

Figure 11. Ice profiles taken at various radial locations for Run 19.

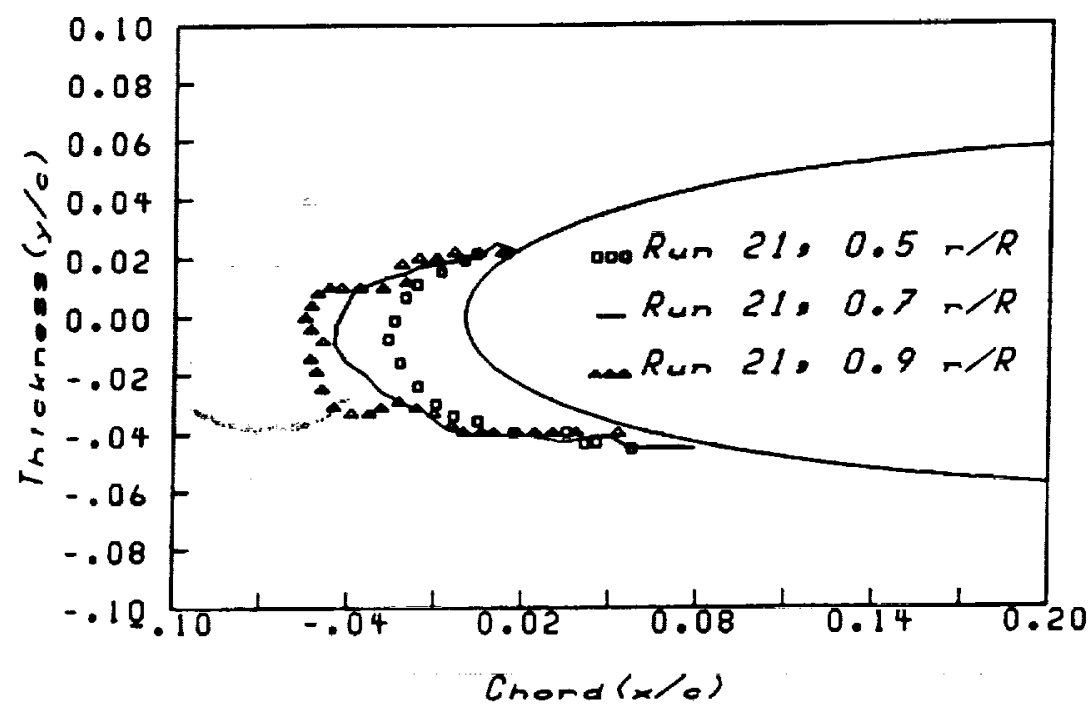

Figure 12. Ice profiles taken at various radial locations for Run 21 . 


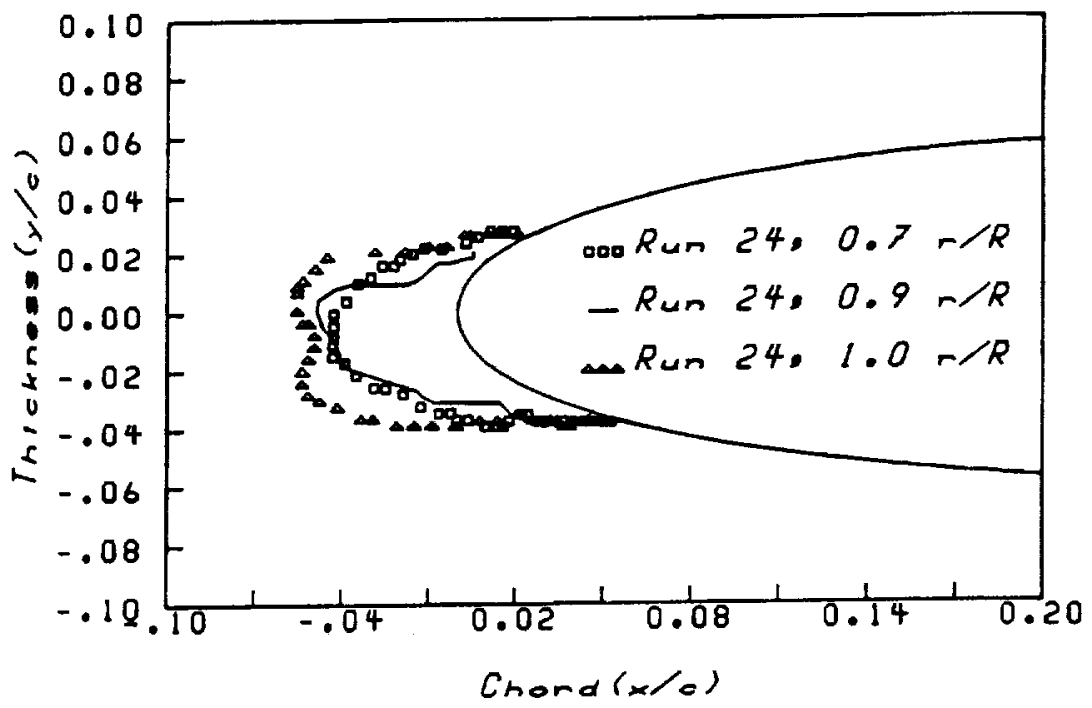

Figure 13. Ice profiles taken at various radial locations for Run 24 .

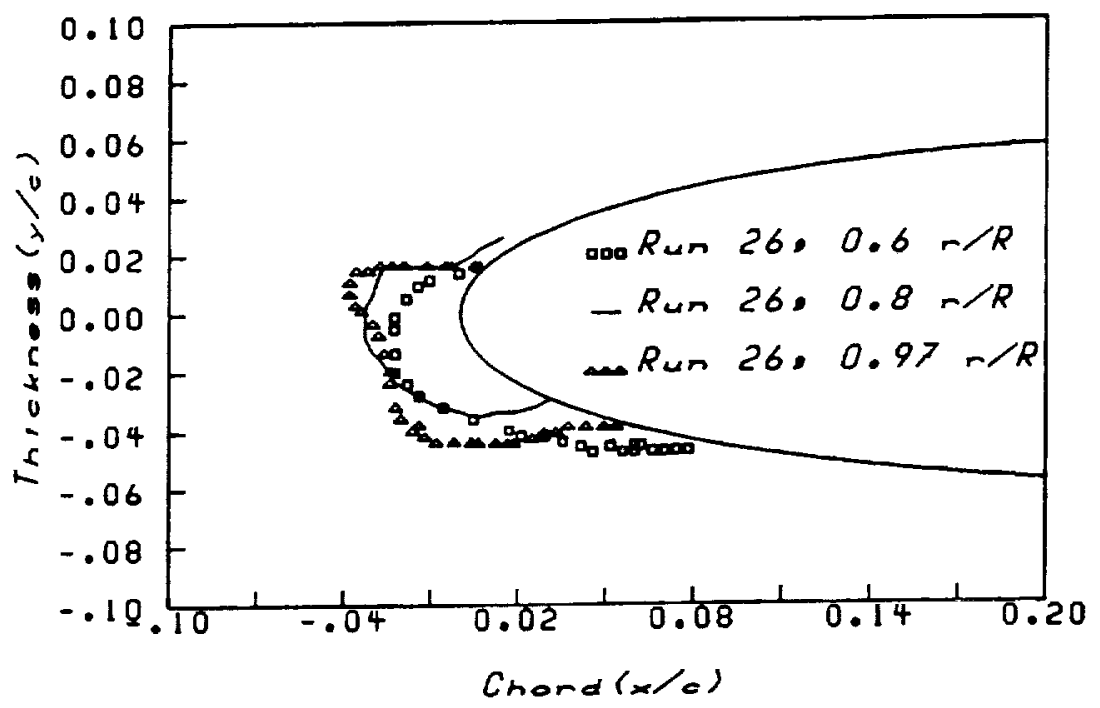

Figure 14. Ice profiles taken at various radial locations for Run 26. 


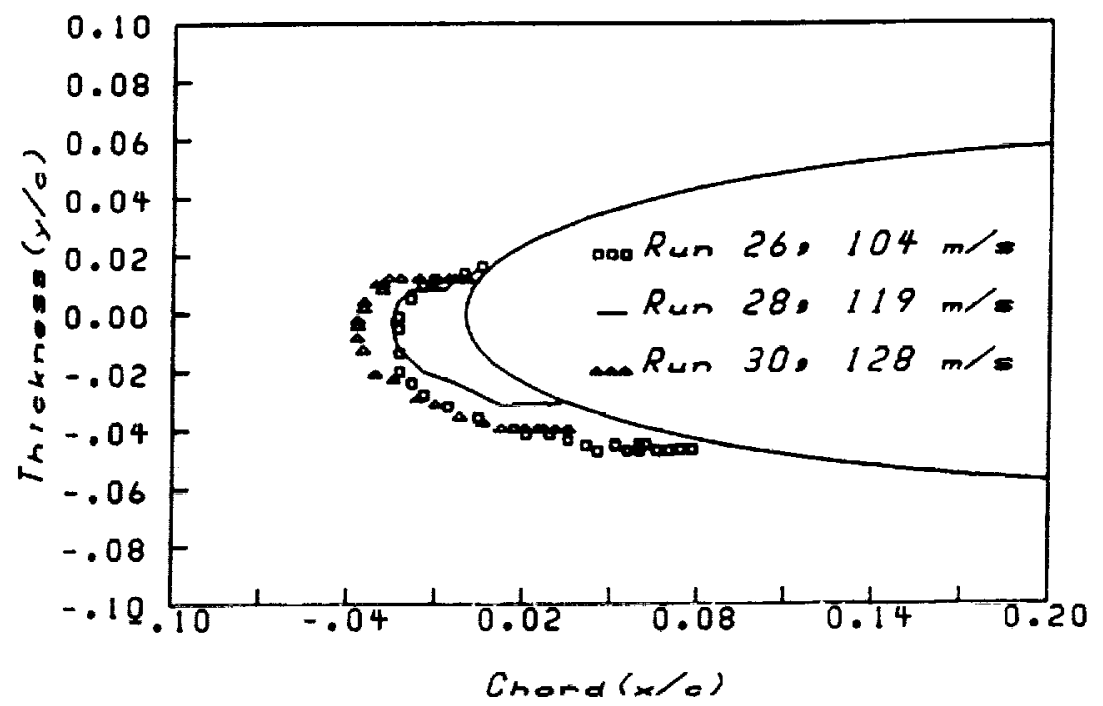

Figure 15. Ice profiles taken at same radial location for various velocities.

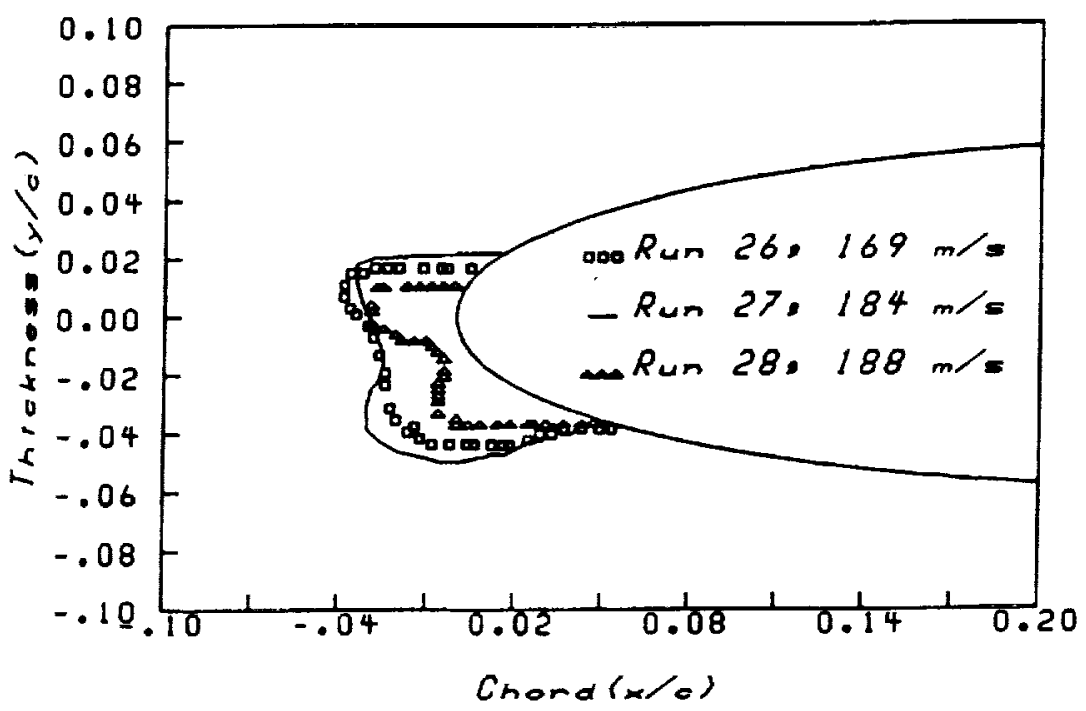

Figure 16. Ice profiles taken at the same radial location for various velocities. 


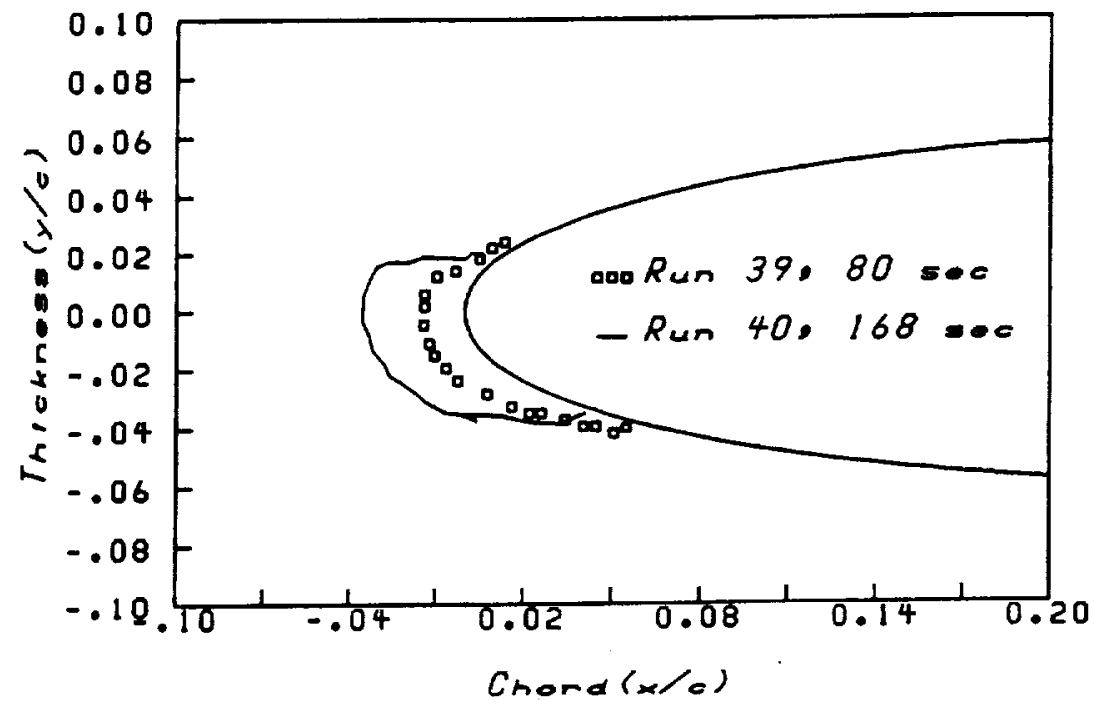

Figure 17. Ice profiles taken at the same radial location for various icing times.

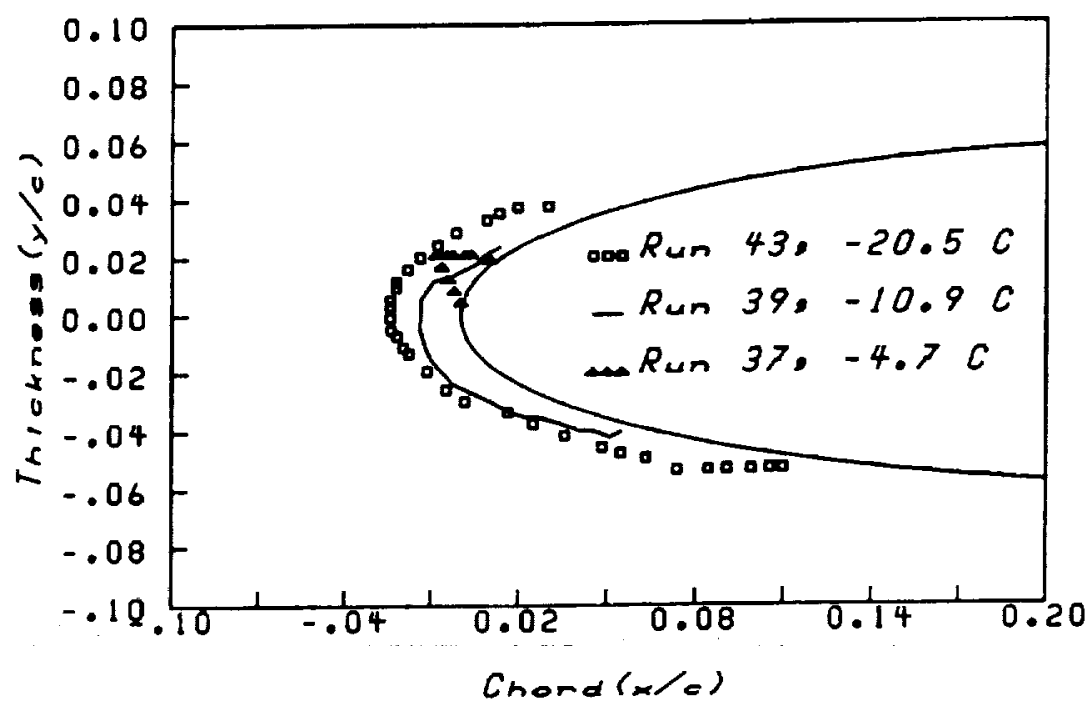

Figure 18. Ice profiles taken at the same radial location for various temperatures. 


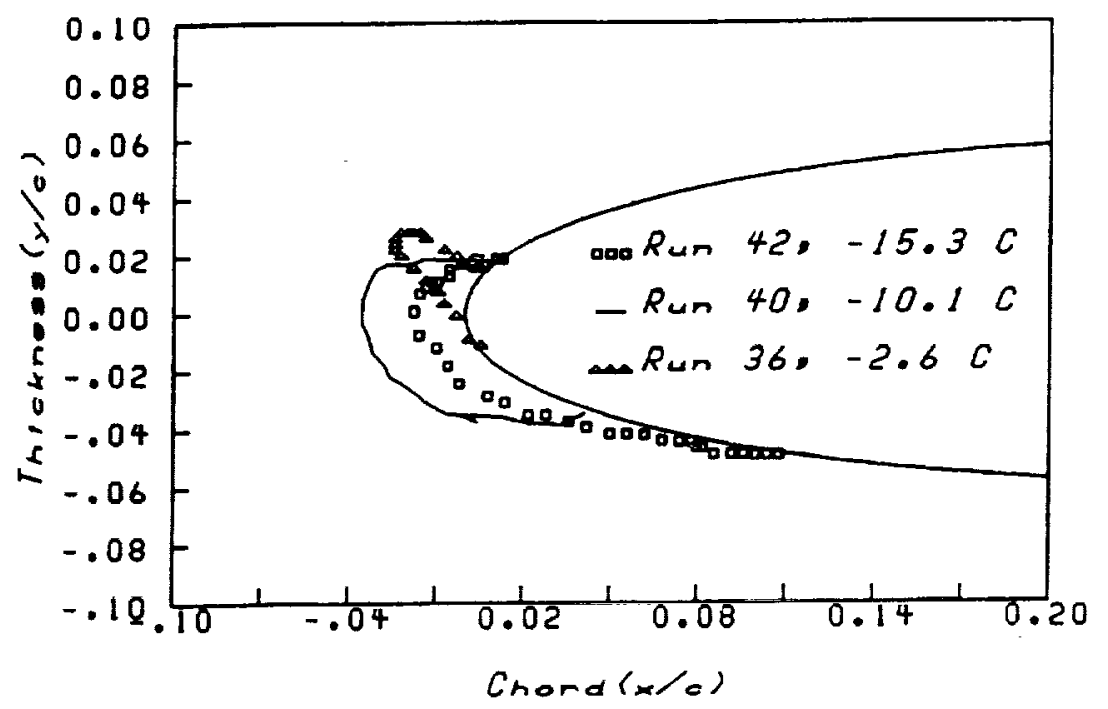

Figure 19. Ice profiles taken at the same radial lacation for various temperatures.

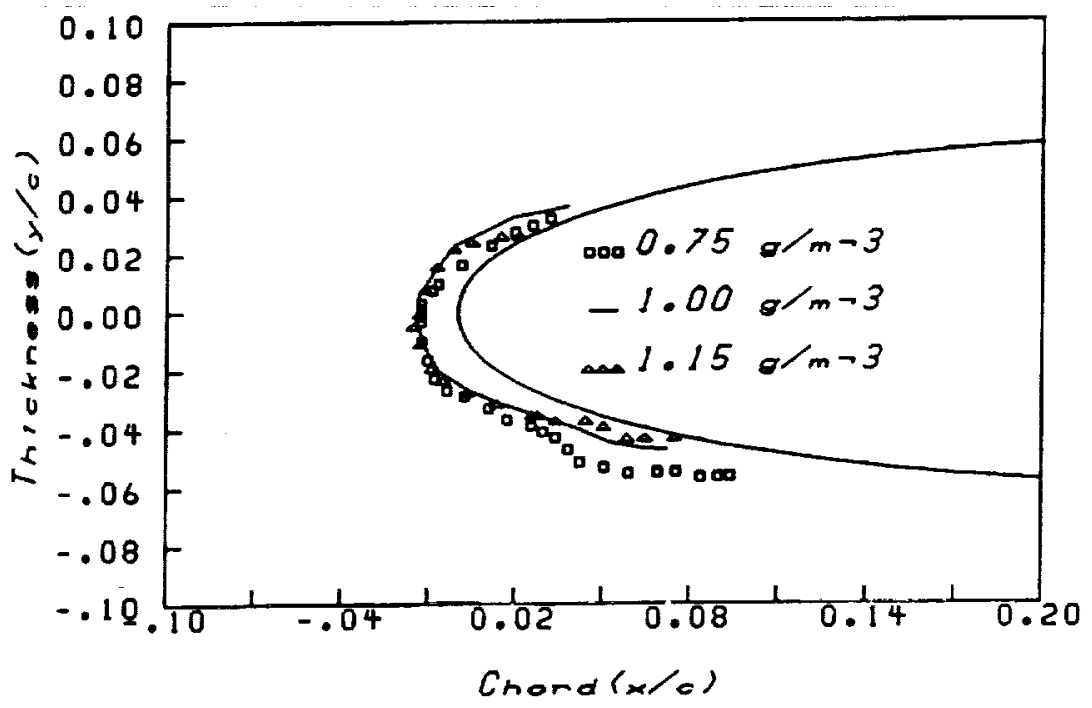

Figure 20. Ice profiles taken at the same radial location for various LWC's. 


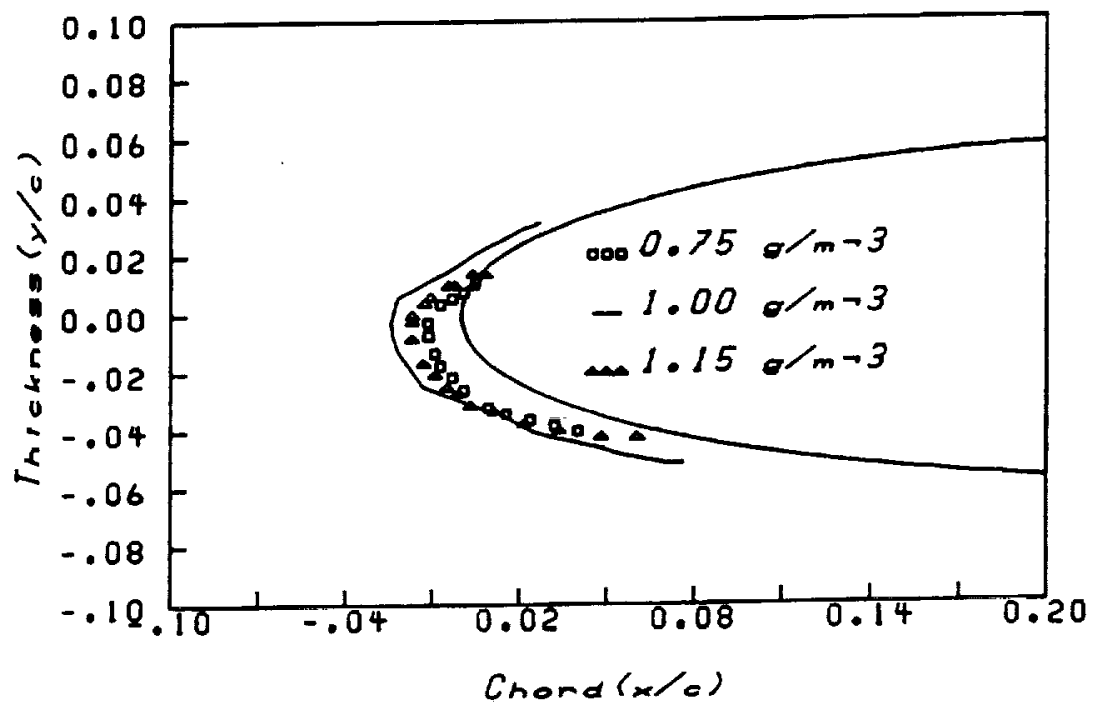

Figure 21. Ice profiles taken at the same radial location for various LWC's.

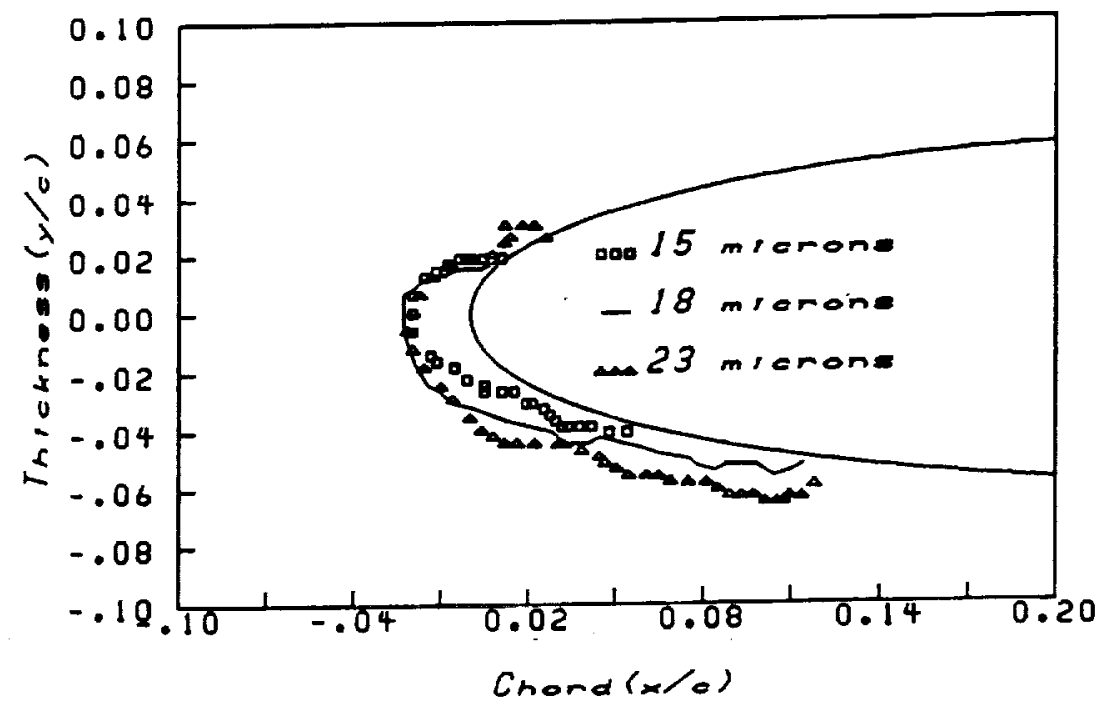

Figure 22. Ice profiles taken at the same radial location for various droplet sizes. 


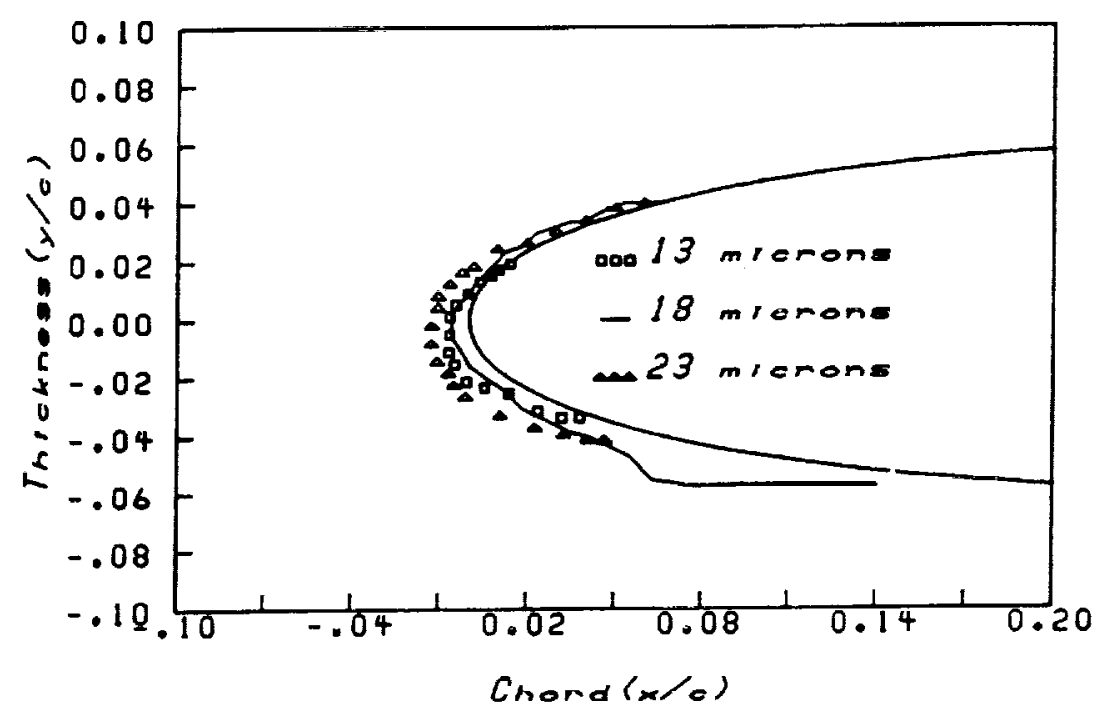

Figure 23. Ize profiles taken at the same radial location for various droplet sizes.

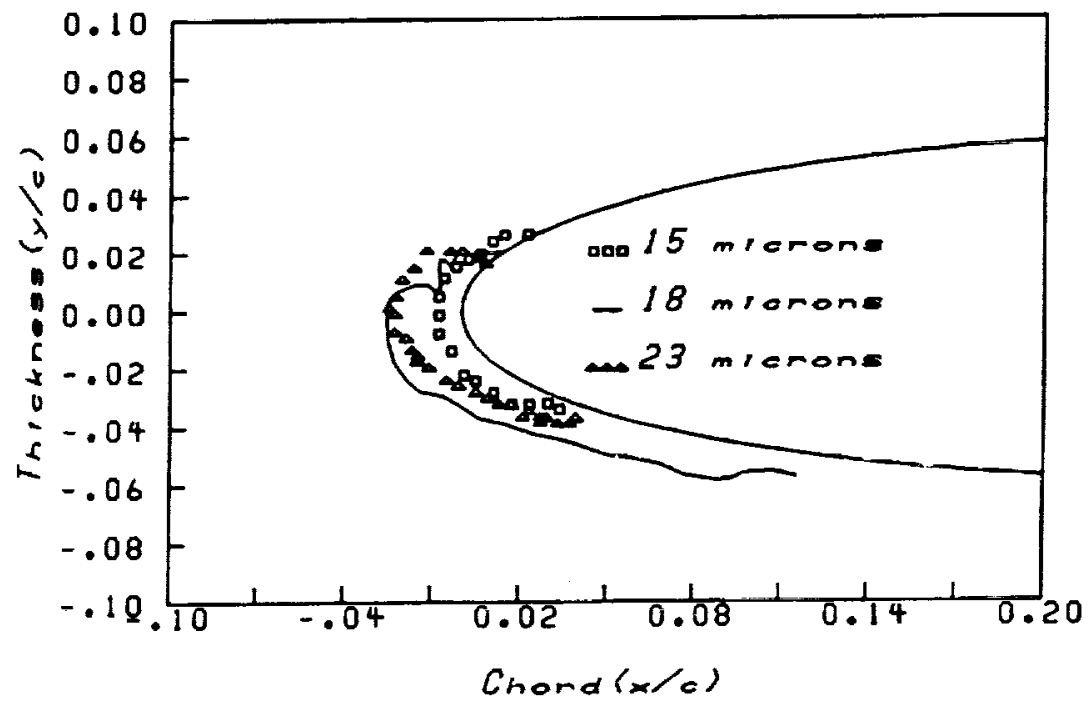

Figure 24. Ice profiles taken at the same radial location for various droplet sizes. 


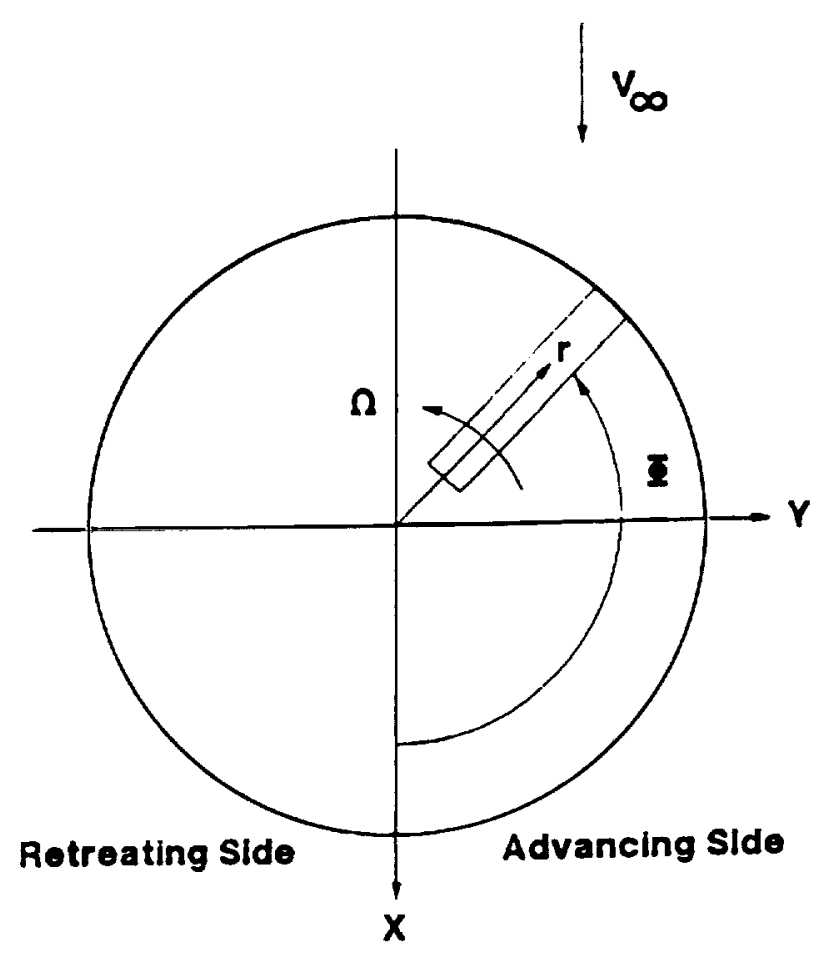

Figure 25. Rotor blade velocity in forward flight.

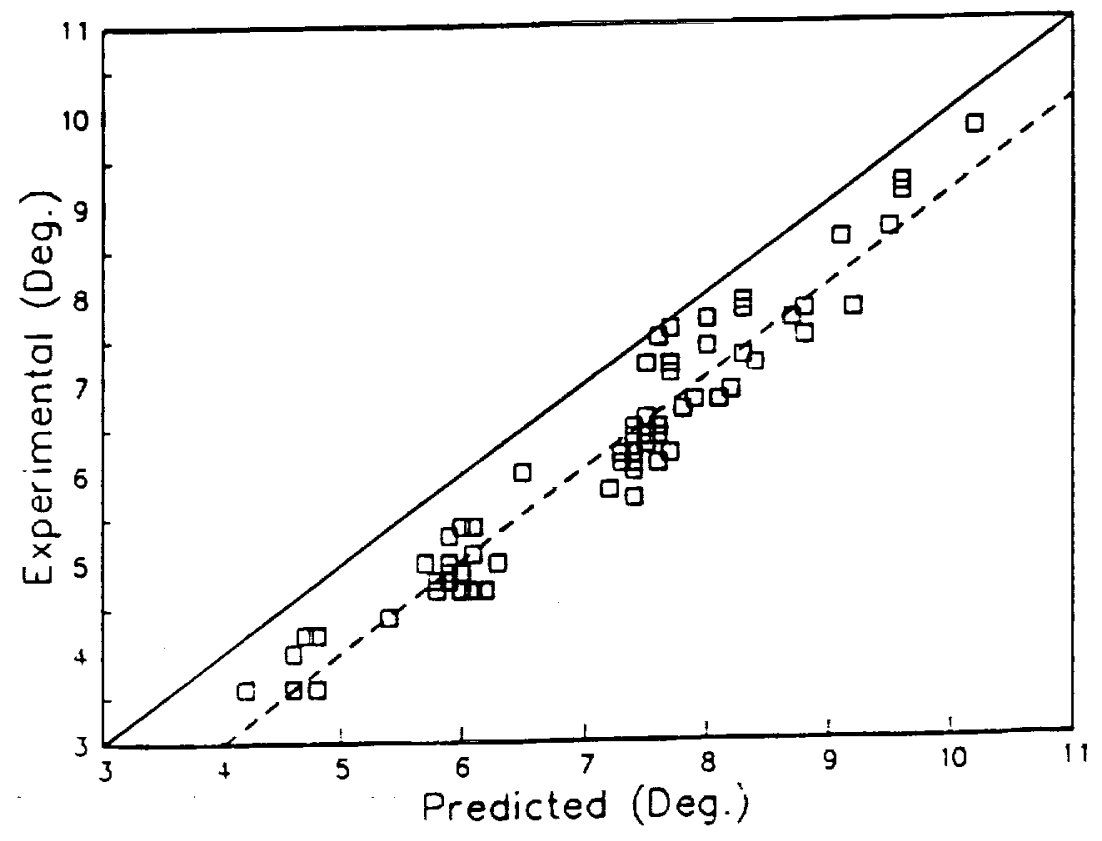

Figure 26. Experimental vs. predicted collective pitch angle. 


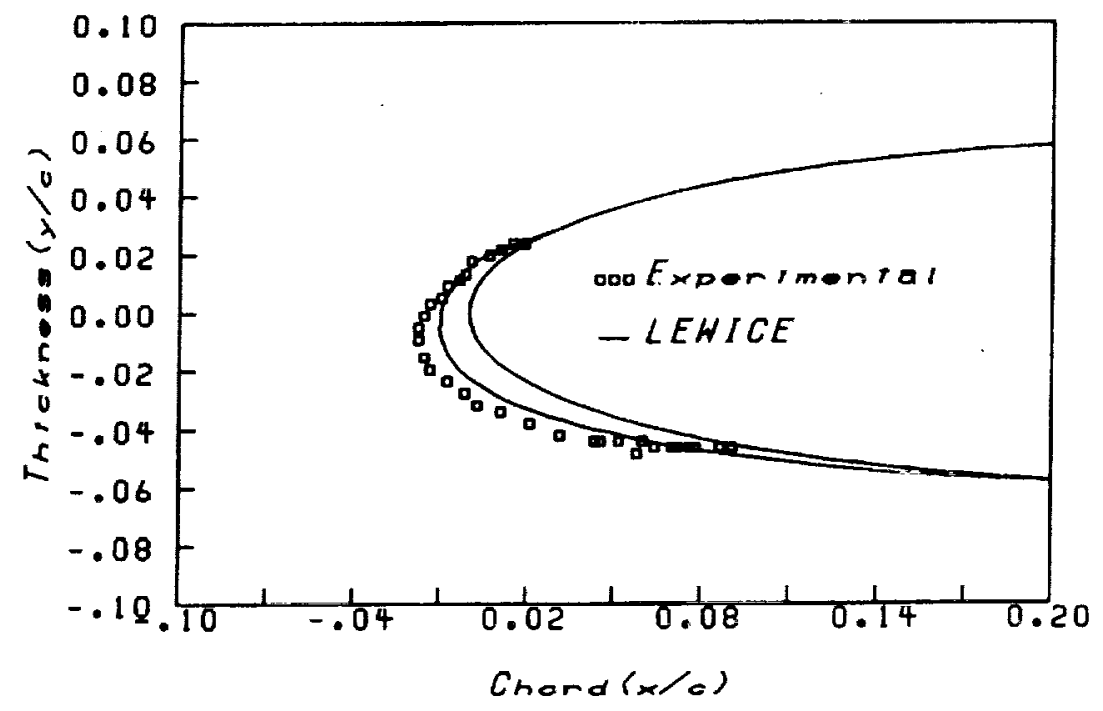

Figure 27. Comparison for Run 33, 50\% radial location.

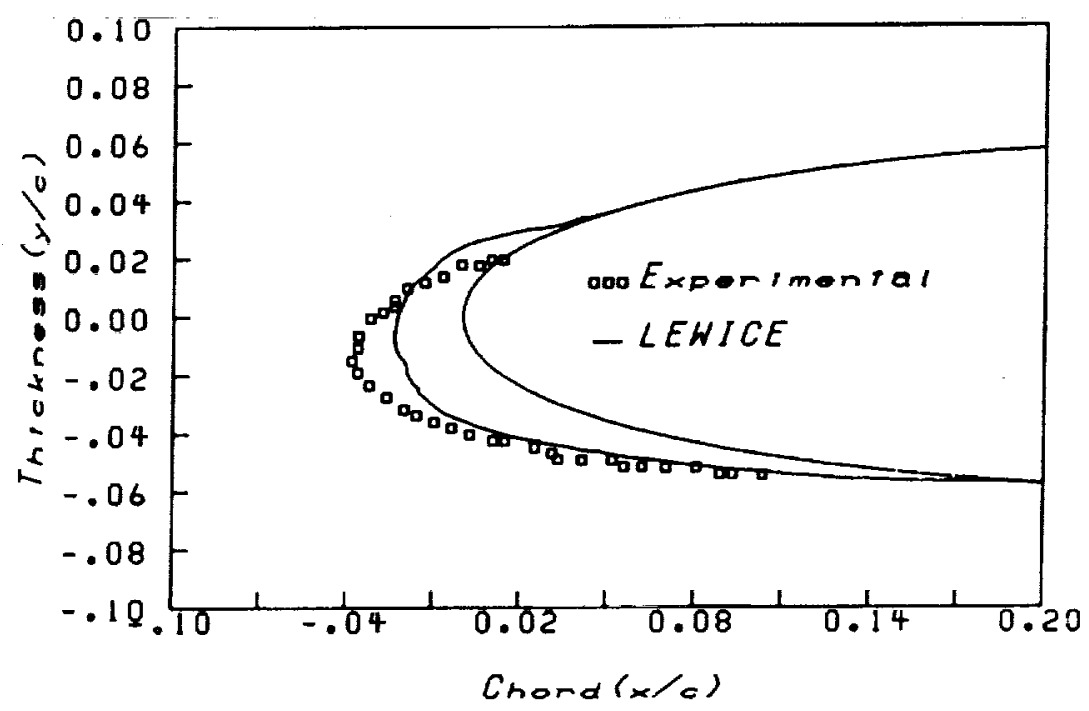

Figure 28. Comparison for Run $94,80 \%$ radial location. 


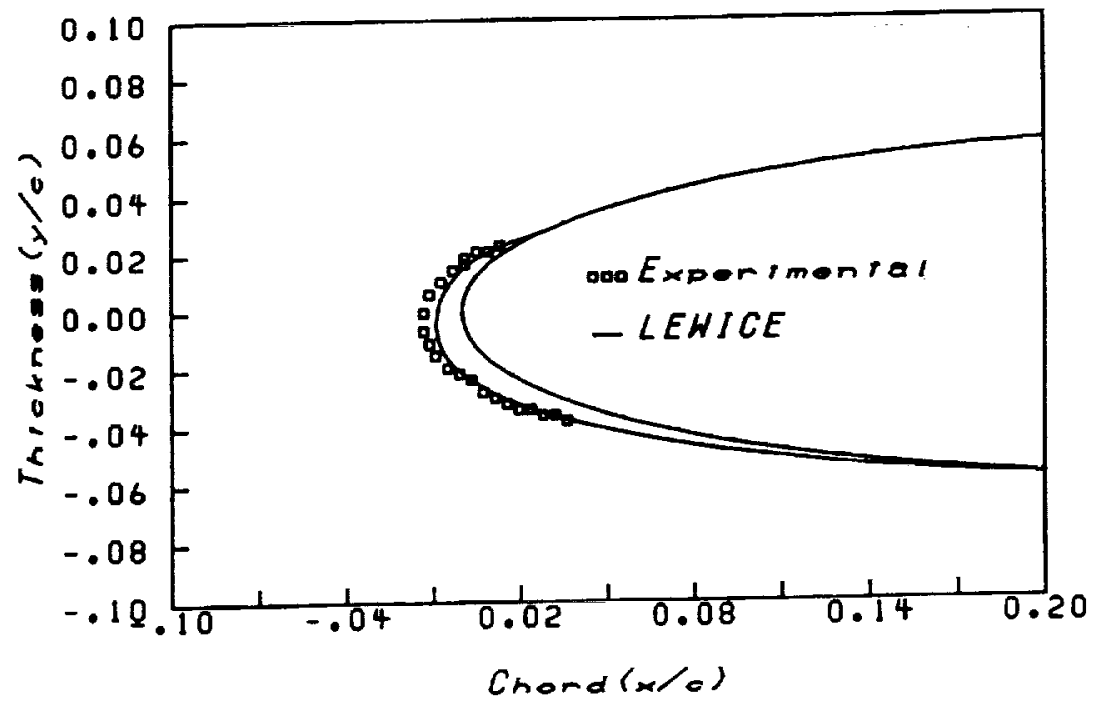

Figure 29. Comparison for Run $34,45 \%$ radial location.

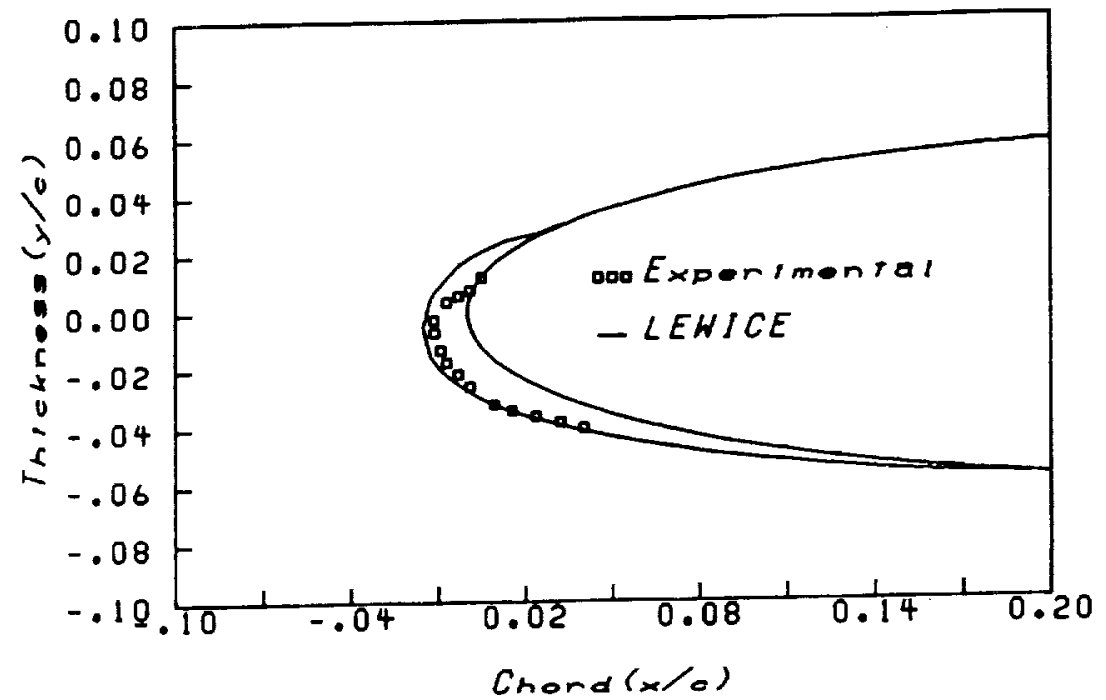

Figure 30. Comparison for Run $74,50 \%$ radial location. 


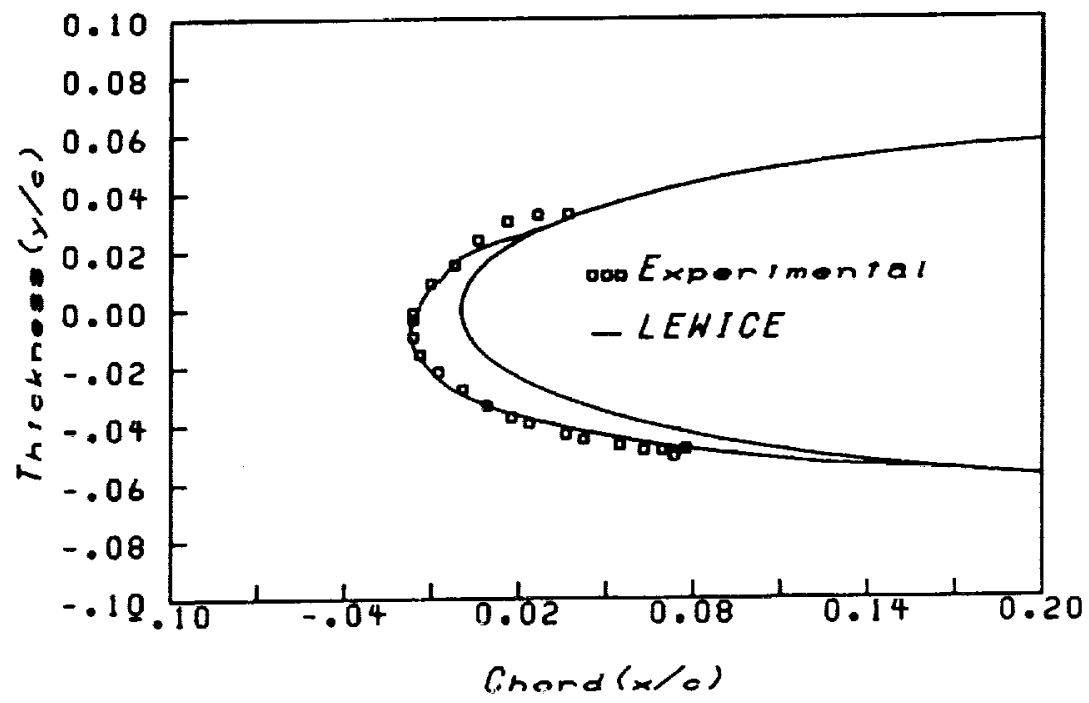

Figure 31. Comparison for Run $79,39 \%$ radial location.

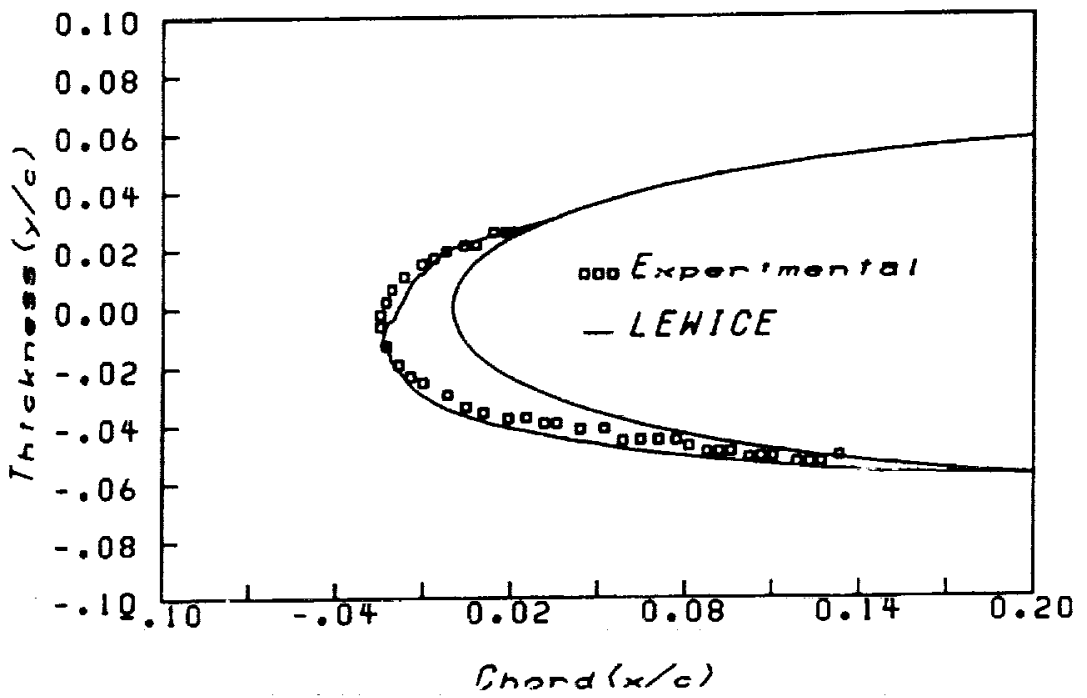

Figure 32. Comparison for Run 24, $50 \%$ radial lcoation. 


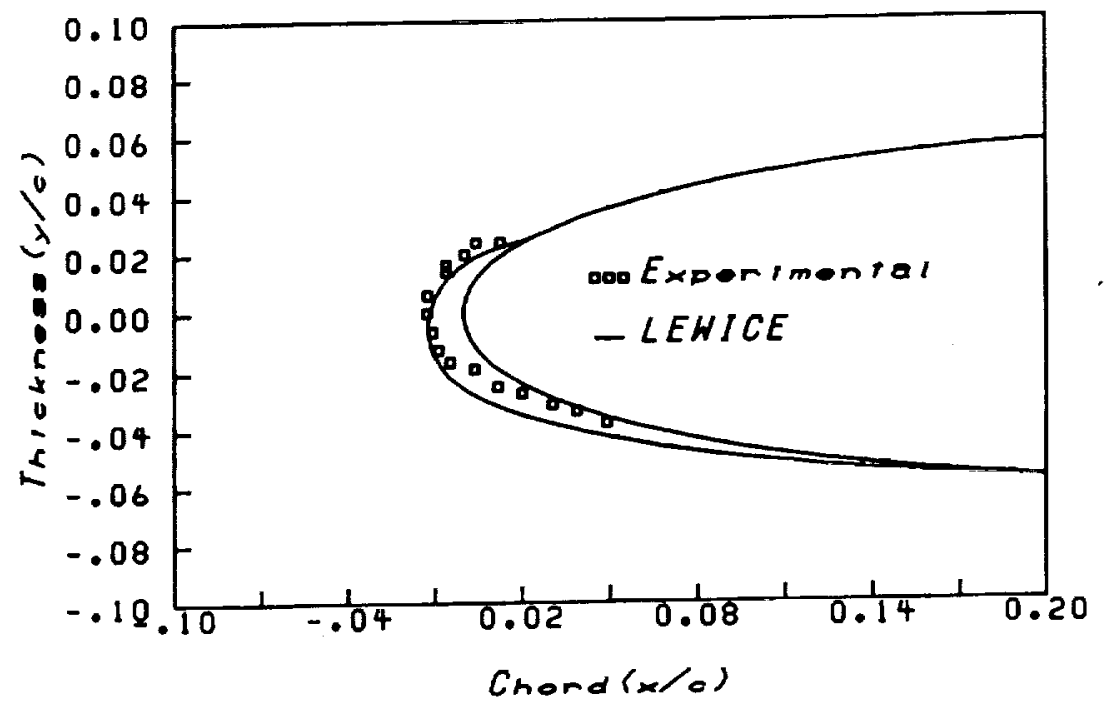

Figure 33. Comparison for Run $41,40 \%$ radial location.

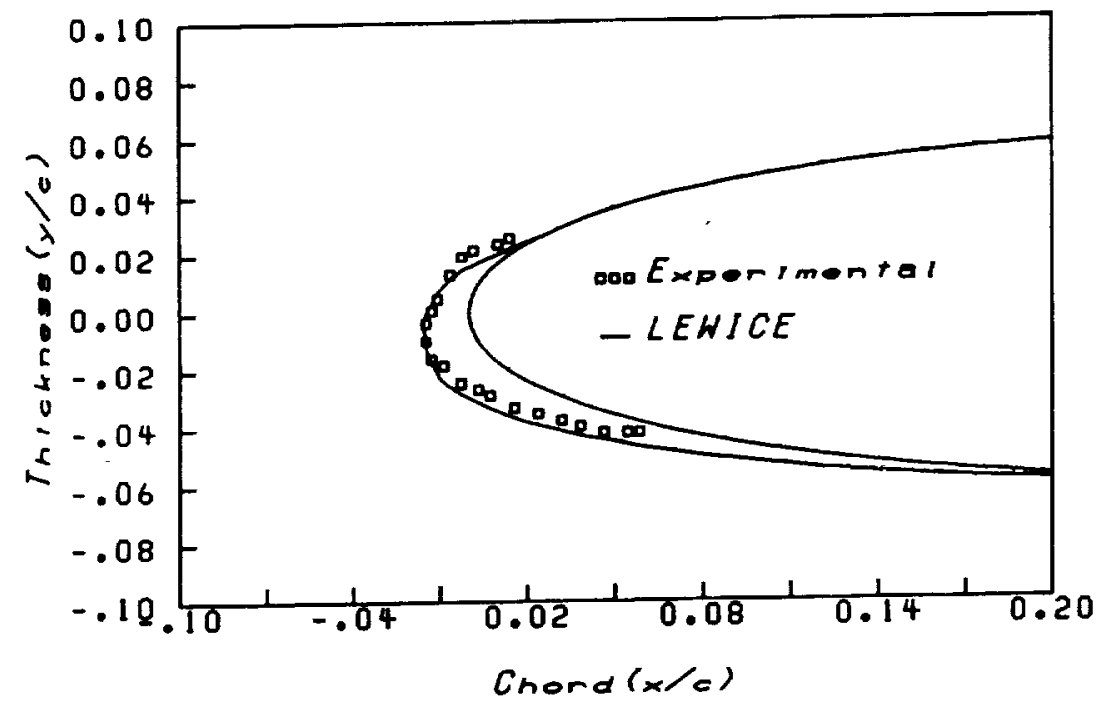

Figure 34. Comparison for Run $68,50 \%$ radial location. 


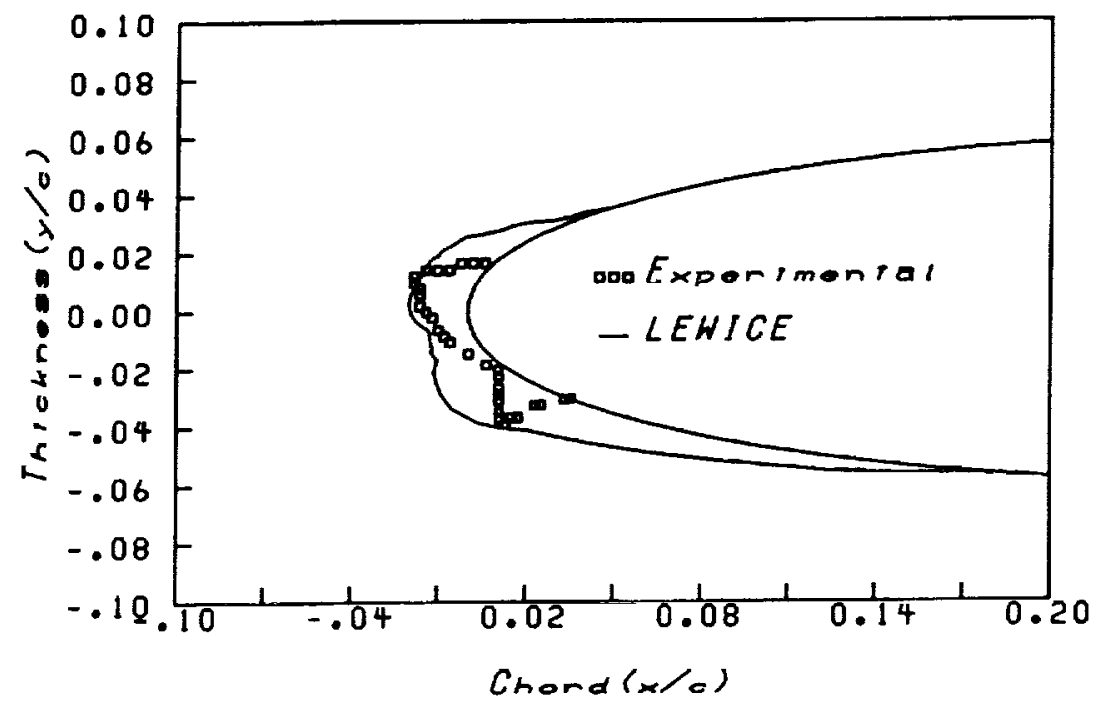

Figure 35. Comparison for Run $89,85 \%$ radial location.

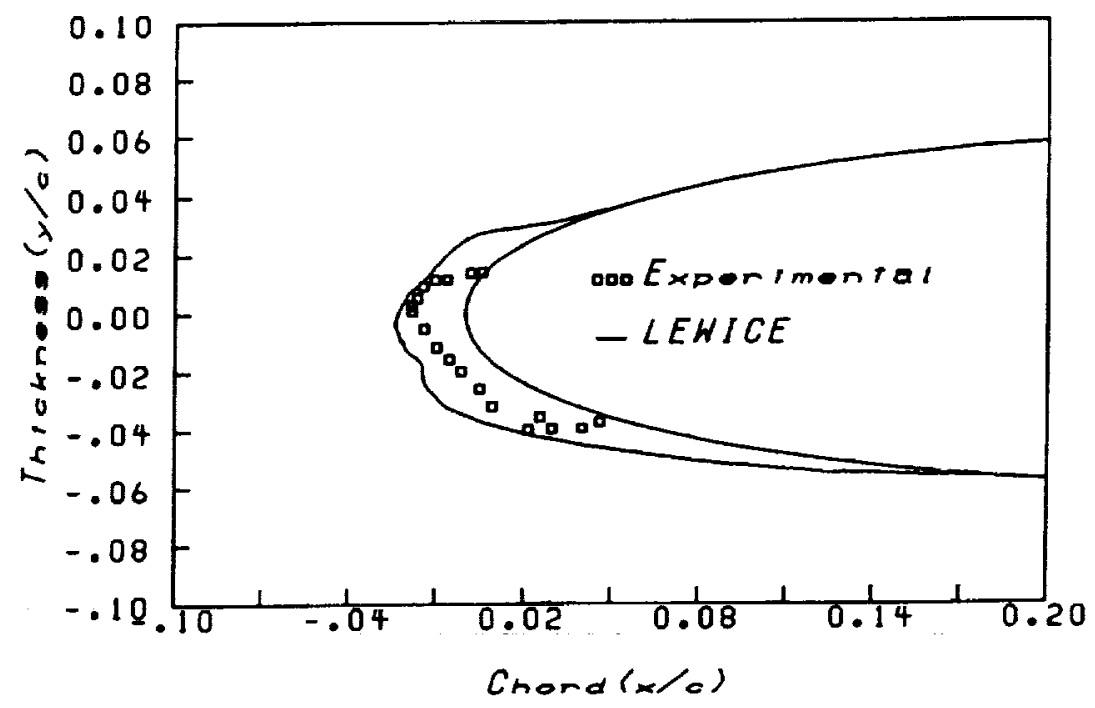

Figure 36. Comparison for Run $87,80 \%$ radial location. 


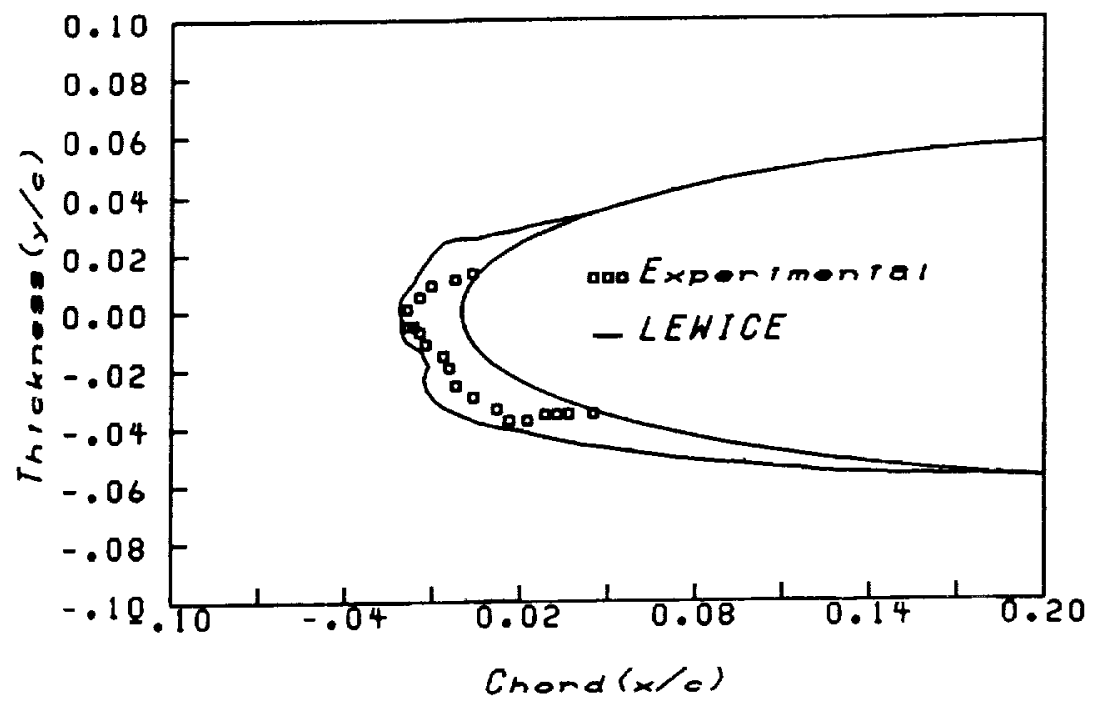

Figure 37. Comparison for Run $88,82 \%$ radial location.

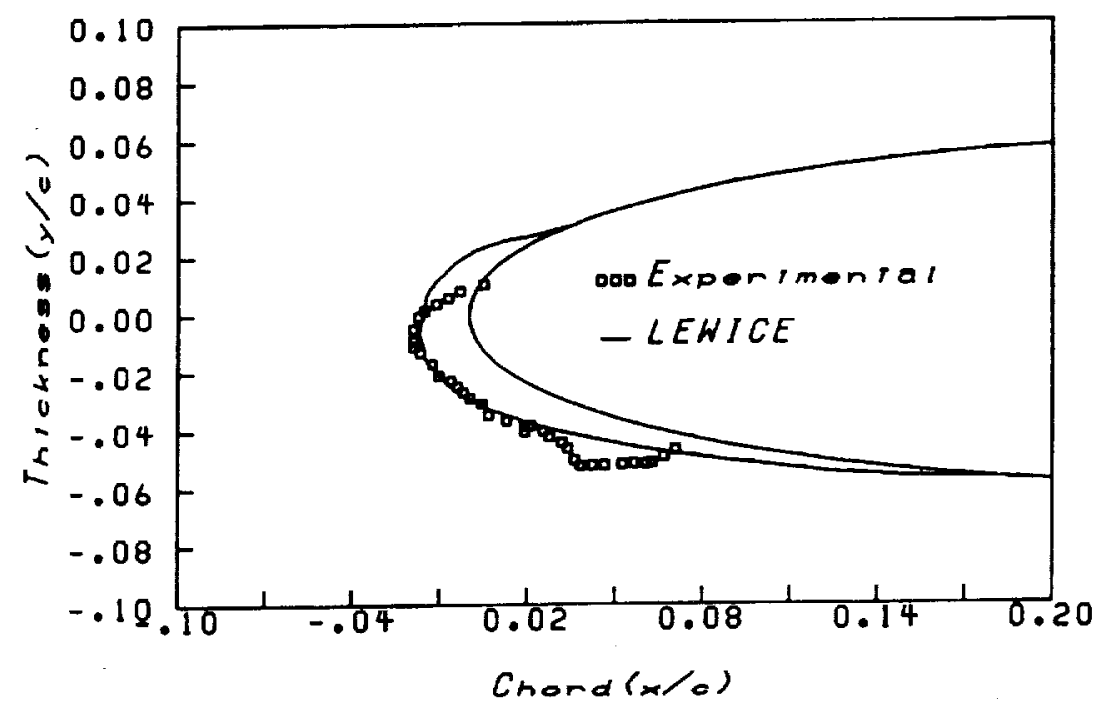

Figure 38. Comparison for Run $73,75 \%$ radial location. 


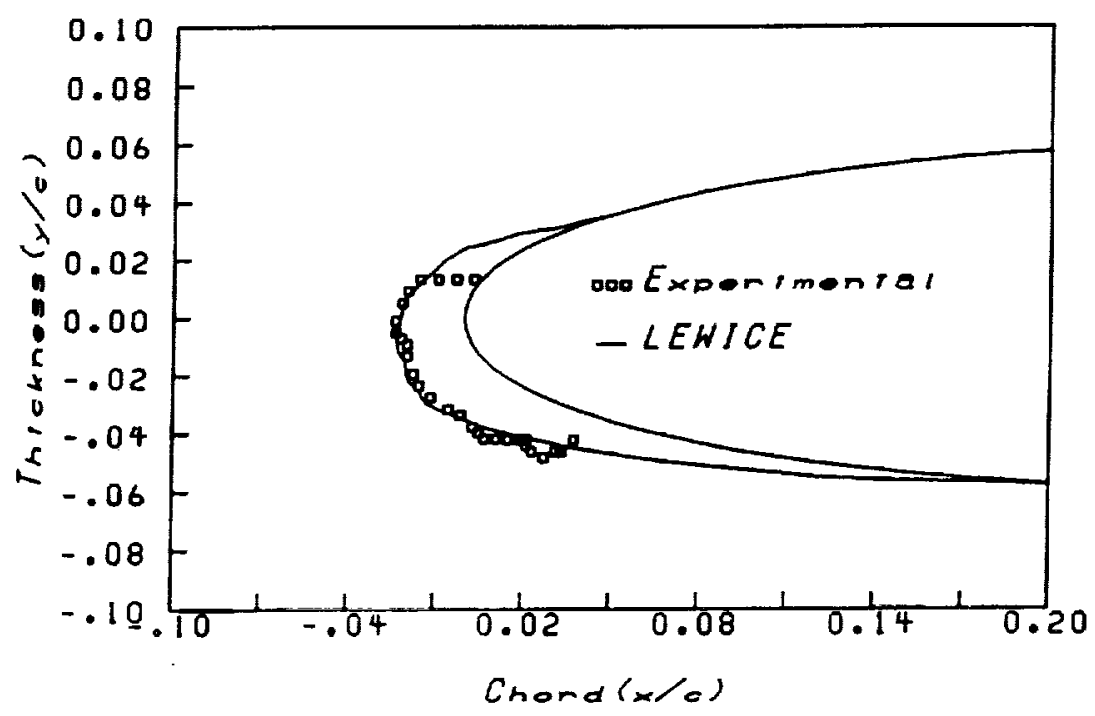

Figure 39. Comparison for Run $71,79 \%$ radial location.

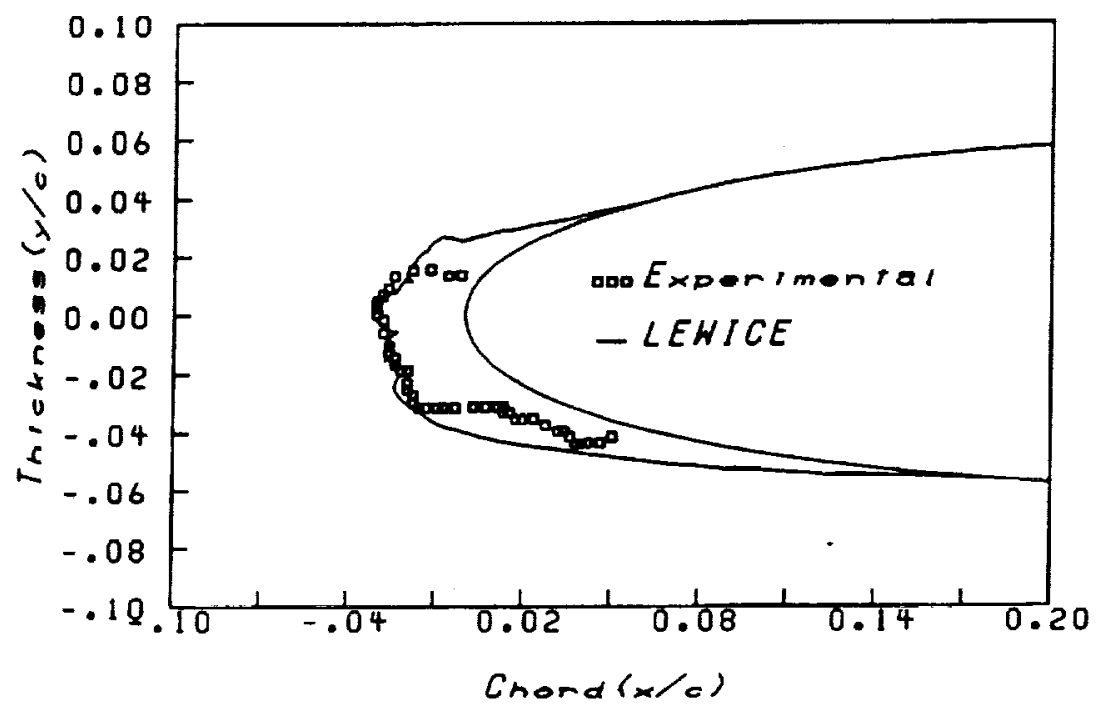

Figure 40. Comparison for Run $51,85 \%$ radial location. 


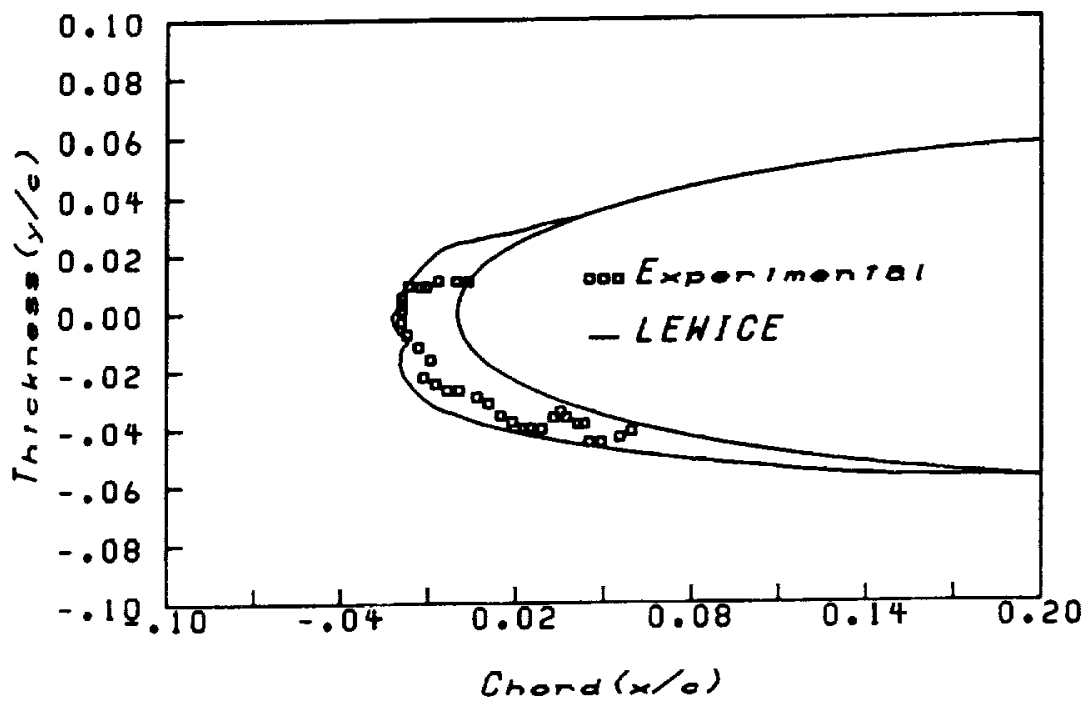

Flgure 41. Comparison for Run $97,79 \%$ radial location.

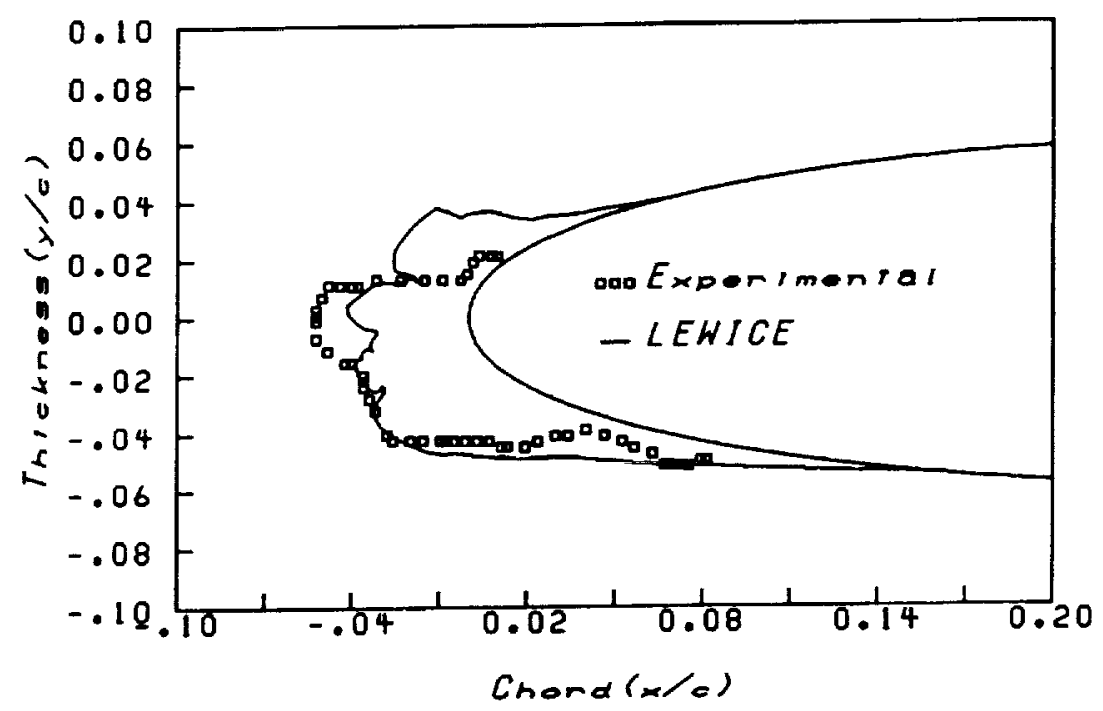

Figure 42. Comparison for Run 52, $90 \%$ radial location. 


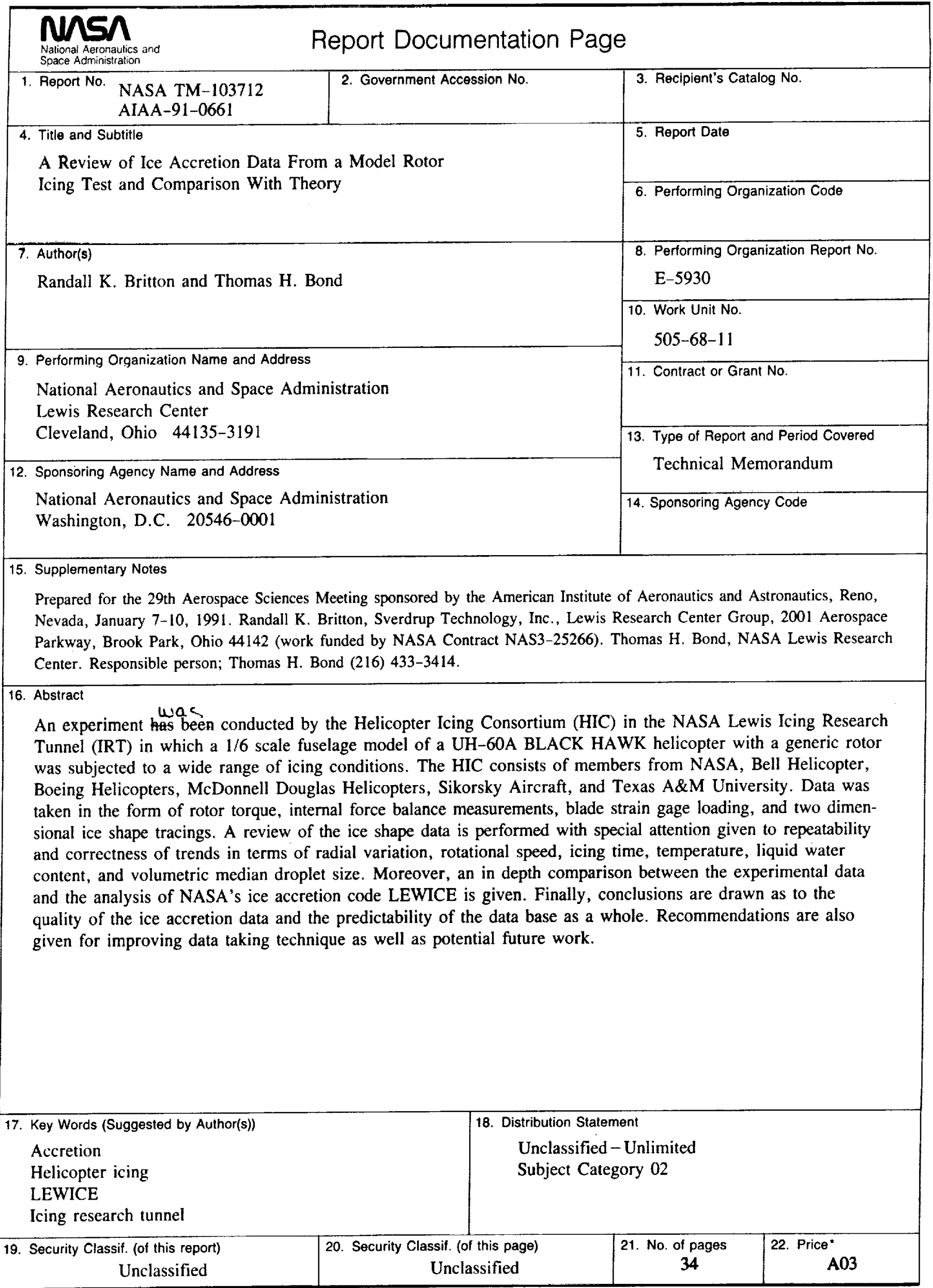

